\title{
Le facce d'un diamante. Appunti per una storia dell'immediatezza nella procedura penale italiana
}

\author{
Facets of a Diamond. Notes for a History of the \\ Immediacy in the Italian Criminal Procedure
}

Marco Nicola Miletti ${ }^{1}$

Università di Foggia, Italia marco.miletti@unifg.it

http://orcid.org/0000-0001-9899-1380

\begin{abstract}
Il saggio ripercorre alcune tappe dell'evoluzione del principio di immediatezza nella procedura penale italiana, entro l'arco cronologico compreso tra la fine del secolo XVIII e il codice Finocchiaro-Aprile del 1913. Dopo una breve rassegna delle diverse definizioni del lemma e un cenno diacronico alla demarcazione dal concetto di oralità, la ricerca muove dagli spunti offerti da 'pionieri' quali Francesco Mario Pagano e Niccola Nicolini; esamina la letteratura europea (francese e, soprattutto, tedesca) che permeò la riflessione dei giuristi italiani; quindi si addentra nella stagione post-unitaria. Quest'ultima fu contrassegnata dal divario tra un codice di rito (1865) ancora prettamente inquisitorio e le istanze d'una dottrina tutt'altro che compatta: se i primi commentari e, con maggiore intransigenza, la scuola carrariana classificavano l'immediatezza tra i canoni inderogabili della giustizia liberale, la scuola positiva vi scorgeva un indebito cedimento alle interferenze popolari ed emotive nel dibattimento. La lunga elaborazione del codice Finocchiaro-Aprile non solo stimolò un serrato confronto dottrinale ma risentí di quel movimento per l'oralità che, secondo Chiovenda, avrebbe modernizzato il rito civile e penale.

PAROlE CHIAVE: Immediatezza; Oralità; Movimento per l'oralità; Procedura penale italiana post-unitaria; Codice di procedura penale 1865; Codice di procedura penale 1913; Scuola classica e scuola positiva; Dibattimento.
\end{abstract}

1 Professore ordinario Università di Foggia, Italia. 
ABSTRACT: The essay traces some stages in the evolution of the principle of immediacy in the Italian criminal procedure, within the time span between the end of the eighteenth century and Finocchiaro-Aprile's code (1913). After a brief review of the different definitions of the term and a mention of the distinction between immediacy and orality, the research begins with ideas offered by 'pioneers' such as Francesco Mario Pagano and Niccola Nicolini; than it examines the European (French and, especially, German) Literature which had the greatest influence on the Italian one; finally, it studies the Italian post-unitarian criminal science. The latter had to do with a still inquisitional code (1865). For their part, the scholars were by no means compact: the first commentaries and, even more, Carrara's school considered immediacy a non-negotiable principle of the liberal justice; the positivist school feared that the rule could favour popular and emotional interferences in the trial. The long elaboration of Finocchiaro-Aprile's code stimulated a heated debate and inserted the criminal procedure studies into the "orality movement» led by Giuseppe Chiovenda.

KEYwords: Immediacy; Orality; Orality Movement; Post-unitarian Criminal Procedure in Italy; Criminal Procedure Code 1865; Criminal Procedure Code 1913; Classic School and Positivist School; Trial.

Sommarıo: Introduzione; 1. Immediatezza e oralità: corollari o categorie autonome?; 2. Dall'antica «eloquenza del corpo» alla «muraglia» medievale; 3 . Livre de la nature e vólti senza maschera: Bentham e Nicolini; 4. Lezioni dall'Europa: impression e Unmittelbarkeit; 5. II primo codice italiano: «troppe eccezioni»; 6. II divario tra princípi e norme: la processual-penalistica 'moderata'; 7. Nella luce del meriggio: la crociata carrariana; 8. Contro il mito dell'oralità: la sfida positivista; 9. Resistenze della giurisprudenza; 10. La stagione di Finocchiaro-Aprile; 11. Cenno agli sviluppi novecenteschi; Conclusioni; Bibliografia.

\section{INTRODUZIONE}

L'emergenza Covid-19 ha riportato alla ribalta l'eterea categoria dell'immediatezza del processo penale. Gli studiosi italiani, che se ne sono occupati anche per effetto delle incursioni della giurisprudenza costituzionale e di legittimità e delle reazioni del legislatore, hanno 
considerato l'affievolimento dell'immediatezza sintomo non trascurabile d'un quadro degenerativo piú composito, che comprende l'arretramento del focus probatorio dalla fase dibattimentale alle indagini preliminari, il reiterato tradimento delle promesse accusatorie, l'indebolimento di non secondari pilastri costituzionali della giustizia penale ${ }^{2}$.

Un'analisi di lungo periodo sembra dar corpo al sospetto che il principio in questione si stia eclissando insieme con l'universo epistemologico cui apparteneva: un mondo nel quale le prove giudiziarie erano soprattutto fatti o fenomeni agevolmente replicabili sotto gli occhi sapienti del giudice e lo sguardo partècipe della comunità, e non complessi esami chimico-fisici, clinici, neurologici, algoritmici da allestire in laboratori altamente specializzati e solitamente appartati. Sullo sfondo aleggia poi la consapevolezza 'filosofica' che il processo è «pur sempre una mediazione»: nessuno strumento probatorio potrà «mai far rivivere ciò che non è piú», superare l'umana finitezza «per afferrare attraverso le voci e le carte il senso di cose passate» ${ }^{3}$.

L'esatto significato del lemma, e quindi la portata d'un eventuale contenuto precettivo, non sono univoci. Le definizioni, per vero, si assomigliano; cambia, però, l'accentuazione sull'uno o sull'altro elemento qualificante. Si oscilla da un minimum che esaurisce l'immediatezza nell'identità tra organo che acquisisce la prova e organo decidente ${ }^{4}$, al

2 LORUSSO, Sergio. Il fascino indiscreto della "mediatezza". Sistema penale, 23 novembre 2020, spec. p. 1-3 (principio etereo); MAZZA, Oliviero. Tradimenti di un codice. La Procedura penale a trent'anni dalla grande riforma. Torino: Giappichelli, 2020. Il XXXIV Convegno dell'Associazione tra gli Studiosi del processo penale, in ricordo di Franco Cordero (27-28 ottobre 2020), ha avuto ad oggetto Immediatezza e processo penale. In quella sede FERRUA, Paolo. Teorie della prova: dialogo con Franco Cordero. Dis-Crimen, 16 dicembre 2020, p. 15-18 ha proposto una sintesi della recente evoluzione giurisprudenziale e legislativa del concetto.

3 MASSA, Michele. Contributo all'analisi del giudizio penale di primo grado. Milano: Giuffrè, 1964, p. 269. L’Autore si valeva d'una notazione parimenti 'esistenzialista' di Giuseppe Capograssi.

4 FOSCHINI, Gaetano. Sistema del diritto processuale penale. II. $2^{\mathrm{a}}$ ed. Milano: Giuffrè, 1968, p. 383-384 (per il quale, invero, l'immediatezza consta non solo dell'immutabilità del giudice ma anche della non delegabilità degli atti dibattimentali); LOZZI, Gilberto. Lineamenti di procedura penale. $10^{\mathrm{a}}$ ed. Torino: Giappichelli, $2020^{\circ}$, p. 317; GERMANO, Riccardo. L'immediatezza e le 
parametro della prossimità quasi fisica, 'sensoriale' tra giudice decidente e prova ${ }^{5}$, sino alla teoria rigorosa che considera immediato solo il giudizio nel quale il decidente non sia in alcun modo «a conoscenza del risultato probatorio» già conseguito dal soggetto che ha raccolto la prova ${ }^{6}$. Non mancano descrizioni 'combinate', peraltro sempre piú debitrici dell'esperienza di altri ordinamenti ${ }^{7}$. Risulta, comunque, pacifico il nesso logico-culturale che

sue contraddizioni: perché i principi non sono dogmi. Rivista italiana di diritto e procedura penale, v. 63, n. 1, 2020, p. 151-177.

5 MASSARI, Eduardo. Il Processo Penale nella nuova Legislazione Italiana. Libro I [...]. Napoli: Jovene, 1934 [ma 1932], p. 120-121: «Il principio della immediatezza intende assicurare al processo una struttura tale da mettere il giudice in grado di percepire, nella via piú diretta e coi propri sensi», tutte le prove delle parti e le «risultanze processuali» (da questa definizione l'Autore faceva discendere le regole dell'immutabilità del giudice del dibattimento e della non delegabilità degli atti probatori: ivi, p. 121); MASSA, Carlo. Il principio dell'immediatezza processuale. In: Studi in onore di Biagio Petrocelli. Tomo secondo. Milano: Giuffrè, 1972, p. 1119 (l'«immediatezza processuale», intesa come contatto non 'intermediato' tra giudice e risultanze dibattimentali, è uno degli elementi che perfezionano l'oralità, insieme con l'identità del giudice e la concentrazione). La definizione di Massari è considerata da UBERTIS, Giulio. Dibattimento (principi del) nel diritto processuale penale. In: Digesto delle discipline penalistiche, III. Torino: Utet, 1987, p. 462 «efficace» ma parziale, perché non tiene conto (ivi, p. 463) del ruolo delle parti. Cfr. anche CHINNICI, Daniela. L'immediatezza nel processo penale. Milano: Giuffrè, 2005, p. 15 (l'immediatezza è il «presupposto necessario per un rapporto tra il decidente e la prova che punti all'effettivo accertamento della 'verità giudiziale'»).

6 MASSA, Michele. Contributo all'analisi del giudizio penale di primo grado. Milano: Giuffrè, 1964, p. 282. L'Autore muove dal presupposto che ogni acquisizione probatoria è sempre, inevitabilmente, frutto d'una valutazione.

7 Come anticipato da CAPPELLETTI, Mauro. La testimonianza della parte nel sistema dell'oralità. Contributo alla teoria della utilizzazione probatoria del sapere delle parti nel processo civile. Parte prima. Milano: Giuffrè, 1962, p. 127128, anche per FERRUA, Paolo. Oralità del giudizio e letture di deposizioni testimoniali. Milano: Giuffrè, 1981, p. 283 l'immediatezza in senso spaziale consiste nell'«identità tra il giudice che decide e il giudice che assume la prova»; immediatezza in senso temporale o concentrazione è «la continuità delle operazioni probatorie al fine di permettere al giudice di emanare la decisione» entro un tempo non troppo «distante dal primo contatto con le fonti di prova». Cfr. anche SIRACUSANO, Delfino; GALATI, Antonino; TRANCHINA, Giovanni; ZAPPALÀ, Vincenzo. Diritto processuale penale, II. Milano: Giuffrè, 2011, p. 309-312; AIUTI, Valerio. L'immediatezza presa sul serio. Diritto penale e processo, v. 1, 2019, p. 111. Per una panoramica delle definizioni piú recenti v. GALLUCCIO MEZIO, Gaetano. Il principio di immediatezza è al tramonto?. 
avvince oralità, immediatezza, concentrazione, pubblicità, contraddittorio, libero convincimento: un fil rouge squisitamente storico, che corre parallelo alle metamorfosi post-illuministiche dell'accusatorio ${ }^{8}$ e che legittima pluralità di sfumature e disallineamenti semantici 9

Consapevoli di questo sfuggente tratto identitario, le pagine seguenti proporranno, attraverso tappe selezionate senza alcuna pretesa di esaustività, una ricostruzione del principio di immediatezza nella procedura penale italiana dalle enunciazioni tardo-settecentesche sino all'approdo del codice del 1913. La ricerca intersecherà la trama dottrinale, la travagliata elaborazione legislativa, le oscillazioni giurisprudenziali: e aprirà qualche squarcio sugli apporti 'esterni' della penalistica europea e del diritto processuale civile, o meglio di quel droit savant assimilabile alla teoria generale del processo.

\section{IMMEDIATEZZA E ORALITÀ: COROLLARI O CATEGORIE AUTONOME?}

Nel paradiso post-rivoluzionario dell'accusatorio, magistralmente tratteggiato da Franco Cordero, il processo era il dibattimento e gli

Cassazione Penale, 2020/1, p. 398; SURACI, Leonardo. La parabola dell'immediatezza nel processo penale. Penale. Diritto e Procedura, 18/2/2020, p. 1-15. Sulla concentrazione v. da ultimo CHINNICI, Daniela. L'immediatezza nel processo penale. Milano: Giuffrè, 2005, p. 11-15. Sul principio d'immediatezza nel processo penale tedesco v. RAFARACI, Tommaso. Processo penale tedesco. In Enciclopedia del diritto. Annali. II/1. Milano: Giuffrè, 2008, p. 844-846.

8 Come osserva, però, acutamente FERRAJOLI, Luigi. Diritto e ragione. Teoria del garantismo penale. $9^{\mathrm{a}}$ ed. Roma-Bari: Laterza, 2008, p. 636, il sistema misto ha, sin dalle origini, dimezzato la portata dell'oralità e dei suoi corollari 'chiovendiani', primi tra tutti immediatezza e concentrazione.

9 Già CHIOVENDA, Giuseppe. Relazione sul progetto di riforma del procedimento elaborato dalla Commissione per il dopo guerra. Napoli: Jovene, 1920; poi in CHIOVENDA, Giuseppe. Saggi di diritto processuale civile (1900-1930). Nuova edizione considerevolmente aumentata dei "Saggi" e dei "Nuovi saggi". Volume secondo. Roma: Società Editrice «Foro Italiano», 1931 [rist. anast. Milano: Giuffrè, 1993], p. 27 riconosceva che il vocabolo oralità rappresentava un «complesso» di «principii distinti, per quanto strettamente collegati fra loro». Cosí anche CALAMANDREI, Piero. Opere giuridiche. Volume primo, a cura di Cappelletti, Mauro. Napoli: Morano, 1965, p. 451 (l'«espressione sintetica» oralità indica un «sistema di principî inseparabili»). 
atti dibattimentali erano «un mondo orale». Gli «intransigenti» che, alla vigilia del code d'instruction criminelle, discutevano di giuria nel Conseil d'État sognavano «una decisione emessa a caldo, su memorie acustiche, senza carte» ${ }^{10}$.

Rispetto a questa elementare aspirazione, l'oralità si caricò, nel corso del secolo XIX, d'un ben piú esteso ventaglio di aspettative. Il vocabolo divenne «sintesi di varii principii, altrettanto connessi e inscindibili fra loro quanto le facce d'un diamante» ${ }^{11}$. Il salto di qualità viene di solito ascritto ai progressi - di cui súbito si dirà - della processualcivilistica d'inizio Novecento, trainata dalla pandettistica ${ }^{12}$. Ma in realtà la piú accreditata letteratura processual-penalistica coeva, desiderosa di guarire dalla sindrome di cenerentola ${ }^{13}$, si cimentò in un analogo e non disprezzabile tentativo di delimitazione concettuale.

Nella prima edizione (1895) della sua opera piú sistematica, gli Elementi di procedura penale, Luigi Lucchini affermava che oralità del giudizio significava da un lato "produzione immediata delle prove innanzi al giudice», specie con riguardo alla prova testimoniale; dall'altro «guarentigia e controllo di retta critica probatoria». Dall'edizione del 1905 l'Autore modificava lievemente il testo e riferiva l'oralità «a due momenti del dibattimento: la produzione delle prove, di cui è principalissima la prova testimoniale, e la discussione delle parti», vale a dire la deposizione e l'esposizione «innanzi al giudice $[. .$.$] a viva voce». Per la migliore efficacia$

10 CORDERO, Franco. Procedura penale. $8^{\mathrm{a}}$ ed. Milano: Giuffrè, 2006, n. 84.34, p. 951.

11 CHIOVENDA, Giuseppe. Principii di diritto processuale civile. Le azioni. Il processo di cognizione [1923]. Ristampa inalterata con prefazione del Prof. Virgilio Andrioli. Napoli: Jovene, 1980, Pref. alla seconda e alla terza ed., p. XIV.

12 CARNELUTTI, Francesco. La malattia del processo penale italiano. Rivista di diritto processuale, v. 17, 1962, p. 2 ipotizzava che «nel periodo scientifico» o «mimetico» la «scienza del processo penale» avesse vissuto una sorta di «minore età» sotto la «tutela» d'una «sorella maggiore», ossia «a spese della scienza del processo civile».

13 MILETTI, Marco Nicola. Un processo per la Terza Italia. Il codice di procedura penale del 1913. I: L'attesa. Milano: Giuffrè, 2003, p. 9-11; MILETTI, Marco Nicola. Un vestito per Cenerentola. L'identità del diritto processuale penale all'alba della Repubblica. In: NEGRI, Daniele; PIFFERI, Michele (a cura di). Diritti individuali e processo penale nell'Italia repubblicana. Milano: Giuffrè, 2011, p. 374-375. 
del principio, il penalista veneto raccomandava di lasciare quanto piú possibile «in disparte [...] le risultanze scritte dell'istruttoria»: queste ultime - spiegavano le successive edizioni degli Elementi - specie se contenenti deposizioni testimoniali rischiavano di «preoccupare l'animo del giudice [...], a detrimento delle guarentigie processuali e della verità giudiziale» ${ }^{14}$. Il primo tra $\mathrm{i}$ «canoni» che Lucchini, coniugando princípi generali e norme codicistiche, faceva discendere dall'oralità consisteva nell'obbligo, per il giudice, di «presenziare incessantemente gli atti del dibattimento», cosí da mettere a profitto la «percezione diretta e completa [...] degli elementi di prova» e di quanto si svolgeva «essenzialmente davanti a lui»; la regola implicava l'identità fisica del giudice sino al termine del processo ${ }^{15}$.

La medesima concatenazione logica lucchiniana si ritrova nella prima edizione (1914) del Trattato di Vincenzo Manzini, in un ideale passaggio di testimone tra scuola classica e indirizzo tecnico-giuridico. Per Manzini il primo requisito dell'oralità era proprio l'immediatezza del procedimento, ossia che il giudice ricevesse «un'immediata, originaria (senza l'interposizione di altri organi attivi) percezione sensoria di tutto il materiale» occorrente a decidere: ciò imponeva di svolgere il processo «oralmente» in presenza di tutti gli interventori e, per l'intera durata, dello stesso giudice. Inoltre - aggiungeva il penalista friulano - il principio di oralità esigeva che la decisione fosse fondata «sull'istruzione orale»: sarebbe stata nulla la sentenza basata «in tutto o in parte» su atti scritti e non letti in dibattimento ${ }^{16}$.

14 LUCCHINI, Luigi. Elementi di procedura penale. Firenze: Barbèra, 1895, n. 283, p. 309-310 (e cosí anche LUCCHINI, Luigi. Elementi di procedura penale. Seconda edizione riveduta e ampliata. Firenze: Barbèra, 1899, n. 283, p. 316); LUCCHINI, Luigi. Elementi di procedura penale. Terza edizione riveduta e ampliata. Firenze: Barbèra, 1905, n. 283, p. 317; LUCCHINI, Luigi. Elementi di procedura penale. Quarta edizione interamente riveduta e ampliata. Firenze: Barbèra, 1920, n. 283, p. 357-358.

15 LUCCHINI, Luigi. Elementi di procedura penale. Firenze: Barbèra, 1895, n. 284, p. 310-311. Cosí anche LUCCHINI, Luigi. Elementi di procedura penale. Terza edizione riveduta e ampliata. Firenze: Barbèra, 1905, n. 284, p. 317-318.

16 MANZINI, Vincenzo. Trattato di procedura penale italiana secondo il nuovo c.p.p. e le nuove leggi di ord. giud. - Volume II. Torino: Fratelli Bocca, 1914, n. 274, p. 3-4. Il testo rimase pressoché invariato nelle edizioni successive: MANZINI, Vincenzo. Trattato di diritto processuale penale italiano secondo il 
Come si vede, il nesso consequenziale oralità - immediatezza era già nitido nei testi fondativi della processual-penalistica, persino prima che Giuseppe Chiovenda intraprendesse, sulla scia della pandettistica ${ }^{17}$, il suo «mirabile apostolato» per l'oralità ${ }^{18}$. L'esordio del movimento chiovendiano, infatti, fu individuato ex post dallo stesso giurista in una conferenza napoletana del 1906: in quella sede egli aveva identificato l'oralità essenzialmente nella «concentrazione», intesa come «possibilità di offrire» al giudice, in un'unica udienza, «un quadro unico e vivente della controversia» ${ }^{19}$.

Fu nella Relazione al progetto di riforma stilato per conto della commissione per il dopo-guerra (1920) che Chiovenda presentò l'oralità come «un complesso» di «principii distinti»: non solo «prevalenza della parola come mezzo d'espressione» (mai, però, al punto da escludere del tutto l'apporto della scrittura), ma anche immediatezza, identità dei giudici, concentrazione. L'immediatezza del rapporto tra il giudicante e le fonti di prova, criterio tanto intuitivo quanto disconosciuto nella prassi, e pienamente dispiegabile solo nel processo orale, esigeva che il giudice

nuovo codice. Con prefazione di Alfredo Rocco Ministro della Giustizia. Volume terzo. Torino: Unione Tipografico-Editrice Torinese, 1932, n. 274, p. 9-10.

CHIOVENDA, Giuseppe. Adolfo Wach. Rivista di diritto processuale civile, 1926; poi in CHIOVENDA, Giuseppe. Saggi di diritto processuale civile (1900-1930). Nuova edizione considerevolmente aumentata dei "Saggi" e dei "Nuovi saggi". Volume primo. Roma: Società Editrice «Foro Italiano», 1930 [rist. anast. Milano: Giuffrè, 1993], p. 267 evocava la battaglia di Wach per l'oralità e l'immediatezza. A riprova della padronanza della letteratura tedesca sul tema v. CHIOVENDA, Giuseppe. Principii di diritto processuale civile [...]. $3^{\text {a }}$ edizione riveduta e notevolmente aumentata. Napoli: Jovene, 1913, § 44 , p. 677, nt. 1.

18 CALAMANDREI, Piero. Oralità nel processo. In: Nuovo Digesto Italiano, IX. Torino: Utet, 1940, p. 178-180; poi in CALAMANDREI, Piero. Opere giuridiche. Volume primo, a cura di Cappelletti, Mauro. Napoli: Morano, 1965, p. 451.

CHIOVENDA, Giuseppe. Le riforme processuali e le correnti del pensiero moderno [Conferenza al Circolo giuridico di Napoli, 11 marzo 1906], Rivista giuridica e sociale, 1907; poi in CHIOVENDA, Giuseppe. Saggi di diritto processuale civile (1900-1930). Nuova edizione considerevolmente aumentata dei "Saggi" e dei "Nuovi saggi". Volume primo, Roma: Società Editrice «Foro Italiano», 1930 [rist. anast. Milano: Giuffrè, 1993], p. 388. Lo stesso Autore (ivi, p. 379, nt. *) datava alla conferenza napoletana l'inizio della sua «propaganda» per l'oralità. 
deliberante avesse «assistito allo svolgimento delle prove [...], [fosse] cioè entrato in diretto rapporto» con i vari soggetti processuali in modo da decidere «in base alla immediata impressione ricevutane, e non in base alla relazione altrui». Da oralità e immediatezza discendeva, per Chiovenda, il principio dell'identità fisica dei giudici durante la trattazione della causa. Infine i princípi suddetti (oralità, immediatezza, identità) non si sarebbero attuati senza la concentrazione della causa in una o poche udienze («dire oralità è quanto dire concentrazione»): solo questa condizione temporale diminuiva le probabilità che il giudice dimenticasse l'«impressione riportata» o che, per un qualsiasi accidente, mutasse in corso di processo ${ }^{20}$. In un articolo del 1924 lo studioso azzardava che l'essenza dell'oralità risiedeva soprattutto nell'immediatezza, indispensabile, «come l'aria [...] per respirare», alla formazione d'un libero convincimento empirico e non aprioristico ${ }^{21}$.

20 CHIOVENDA, Giuseppe. Relazione sul progetto di riforma del procedimento elaborato dalla Commissione per il dopo guerra. Napoli: Jovene, 1920; poi in: CHIOVENDA, Giuseppe. Saggi di diritto processuale civile (1900-1930). Nuova edizione considerevolmente aumentata dei "Saggi" e dei "Nuovi saggi". Volume secondo. Roma: Società Editrice «Foro Italiano», 1931 [rist. anast. Milano: Giuffrè, 1993], p. 27-31. Cfr. anche CHIOVENDA, Giuseppe. Principii di diritto processuale civile [...]. $3^{\text {a }}$ Edizione riveduta e notevolmente aumentata. Napoli: Jovene, 1913, § 44, p. 680-686; CHIOVENDA, Giuseppe. Principii di diritto processuale civile. Le azioni. Il processo di cognizione [1923]. Ristampa inalterata con prefazione del Prof. Virgilio Andrioli. Napoli: Jovene, 1980, Pref. alla seconda e alla terza ed., p. XIV-XV. Pressoché ricalcata sulle parole di Chiovenda la voce di CALAMANDREI, Piero. Oralità nel processo. In: Nuovo Digesto Italiano, IX. Torino: Utet, 1940, p. 178-180; poi in CALAMANDREI, Piero. Opere giuridiche. Volume primo, a cura di Cappelletti, Mauro. Napoli: Morano, 1965, p. 452-453.

21 CHIOVENDA, Giuseppe. Relazione sul progetto di riforma del procedimento elaborato dalla Commissione per il dopo guerra. Napoli: Jovene, 1920; poi in CHIOVENDA, Giuseppe. Saggi di diritto processuale civile (1900-1930). Nuova edizione considerevolmente aumentata dei "Saggi" e dei "Nuovi saggi". Volume secondo. Roma: Società Editrice «Foro Italiano», 1931 [rist. anast. Milano: Giuffrè, 1993], p. 208-210. Sulla priorità dell'immediatezza nell'impostazione chiovendiana dell'oralità v. CAPPELLETTI, Mauro. La testimonianza della parte nel sistema dell'oralità. Contributo alla teoria della utilizzazione probatoria del sapere delle parti nel processo civile. Parte prima. Milano: Giuffrè, 1962, p. 123; CAPPELLETTI, Mauro. L'oralità nel processo civile italiano: ideale contro realtà (1972). In: CAPPELLETTI, Mauro. Giustizia e società. Milano: Edizioni di Comunità, 1972 [rist. 1977], p. 134. 
Lucchini, Manzini e Chiovenda convergevano, dunque, nel considerare l'immediatezza un indefettibile complemento dell'oralità ${ }^{22}$. A condizione, evidentemente, di intendere quest'ultima in senso forte ${ }^{23}$ : non, banalmente, «modalità di escussione delle prove» (ancora oggi, oltretutto, sarebbe plausibile un'oralità senza immediatezza, come accade ad esempio nell'incidente probatorio), bensí affidamento della decisione a un organo che abbia instaurato con la prova un «rapporto diretto» ${ }^{24}$. Estremizzando le premesse dei processual-civilisti (e in particolare di Cappelletti), una monografia di Michele Massa degli anni Sessanta del Novecento affermava perentoriamente che «oralità significa immediatezza» e che la seconda non era «un connotato» della prima o «un principio da questa distinto», bensí «l'oralità stessa spiegata [...] con maggiore sostanziale esattezza» ${ }^{25}$.

Una diversa tesi che ha attraversato per decenni la processualpenalistica italiana tende invece a distinguere immediatezza e oralità. La prima atterrebbe alla escussione della prova, la seconda alla sua assunzione ${ }^{26}$. In quest'ottica, l'immediatezza andrebbe autonomamente intesa come «mancanza di interposizione di un mezzo di prova fra un altro mezzo di prova e il giudice». Cosí concepito, il principio da un lato 'lucra' sulla «legge di natura» che annette uno speciale valore conoscitivo alla

22 FERRUA, Paolo. Oralità del giudizio e letture di deposizioni testimoniali. Milano: Giuffrè, 1981, p. 282-283.

CHINNICI, Daniela. L'immediatezza nel processo penale. Milano: Giuffrè, 2005, p. 34, nt. 81.

ILLUMINATI, Giulio. Il nuovo dibattimento: l'assunzione diretta delle prove. Il Foro Italiano, 111 (1988), pt. V, col. 356. Per un es. di immediatezza senza oralità (l'esame del sordo-muto) v. FERRUA, Paolo. Oralità del giudizio e letture di deposizioni testimoniali. Milano: Giuffrè, 1981, p. 292.

MASSA, Michele. Contributo all'analisi del giudizio penale di primo grado. Milano: Giuffrè, 1964, p. 278-279.

26 Cosí FOSCHINI, Gaetano. Sistema del diritto processuale penale. II. $2^{\mathrm{a}} \mathrm{ed}$. Milano: Giuffrè, 1968, p. 383-385; FOSCHINI, Gaetano. Principio dell'immediatezza e principio della pubblicità. Nota a Cass., $2^{\text {a }}$ sez. pen., 21 gennaio 1953. Rivista italiana di diritto penale, 1953, p. 374; ora in FOSCHINI, Gaetano. Il dibattimento. Studi. Milano: Giuffrè, 1956, p. 132-133. Esattamente inverso il parere di DE NOTARISTEFANI, Raffaele. Del giudizio. In: MORTARA, Lodovico; STOPPATO, Alessandro; VACCA, Guglielmo; SETTI, Augusto; DE NOTARISTEFANI, Raffaele; LONGHI, Silvio (a cura di). Commento al Codice di procedura penale. VI - Codice di procedura penale. Libro Terzo. Torino: Unione Tipografico-Editrice, 1915, p. 586-588. 
prossimità della percezione; dall'altro non si attaglia alle prove indirette, o de relato o di secondo grado ${ }^{27}$, sebbene la lettura possa oralizzare queste ultime ${ }^{28}$ e renderle, cosí, formalmente rispettose del canone di oralità.

\section{Dall'antica «eloquenza del corpo» alla «muraglia» MEDIEVALE}

Si è autorevolmente sostenuto che la mediatezza rientrasse nella dotazione genetica del processo romano-canonico: la scrittura, forma imprescindibile nel rito medievale, costituiva «la muraglia che separava il giudice dagli altri soggetti del processo»; le testimonianze venivano, per lo piú, raccolte da un attuario o cancelliere e non in pubblica udienza $^{29}$. Le pratiche criminali d'età moderna, tuttavia, esaltavano la rilevanza probatoria delle reazioni emotive dell'imputato (trepidatio, titubatio, rossore, pallore), il cui accertamento presupponeva una qualche constatazione 'diretta' da parte dell'organo decidente ${ }^{30}$.

27 Complessa e disordinata la casistica proposta da DE NOTARISTEFANI, Raffaele. Del giudizio. In: MORTARA, Lodovico; STOPPATO, Alessandro; VACCA, Guglielmo; SETTI, Augusto; DE NOTARISTEFANI, Raffaele; LONGHI, Silvio (a cura di). Commento al Codice di procedura penale. VI - Codice di procedura penale. Libro Terzo. Torino: Unione Tipografico-Editrice, 1915, p. 586-588.

28 Il «barbaro neologismo» fu usato da BERENINI, Agostino. Limiti della pro$v a$ in criminale. Brevi considerazioni con particolare riferimento all'articolo 848 del codice di procedura penale. Parma: Luigi Battei, 1887, p. 41, che se ne scusava; poi da MANZINI, Vincenzo. Trattato di procedura penale italiana secondo il nuovo c.p.p. e le nuove leggi di ord. giud. - Volume II. Torino: Fratelli Bocca, 1914, n. 425, p. 452.

29 CAPPELLETTI, Mauro. Il processo civile italiano nel quadro della contrapposizione «civil law»- «common law» (Appunti storico-comparativi). Rivista di diritto civile, v. 9, n. I, 1963, p. 31-64; poi in: CAPPELLETTI, Mauro. Processo e ideologie. Bologna: il Mulino, 1969, p. 311-312.

30 CLARO, Giulio. Liber Quintus Receptarum Sententiarum integer (1568). In: CLARO, Giulio. Opera omnia; sive Practica civilis, atque criminalis [...]. Venetiis: Apud Baretium Baretium, 1640, § Fin., quaest. XXI, n. 39, pp. 271-272; FARINACCI, Prospero. Praxis et theoricae criminalis Partis Primae Tomus Secundus. Lugduni: Sumptibus Iacobi Cardon, 1634, quaest. LII, n. 40, p. 365. Nel raccogliere la deposizione dei testimoni, il notaio (segnalava LESSONA, Carlo. Teoria delle prove nel diritto giudiziario civile italiano [...]. Vol. IV. Seconda edizione interamente riveduta. Firenze: Cammelli, 1908, n. 339, p. 428) 
Dall'antico regime provengono, dunque, indicazioni contrastanti. È verosimile che giudice e parti, specie nel rito civile, non si guardassero nemmeno negli occhi. Ma è altrettanto indubbio che la precettistica indirizzata al magistrato desse per scontato che questi incrociasse regolarmente l'inquisito. È corretto, allora, far decorrere solo dalle istanze dell'illuminismo maturo e dalle norme codicistiche una qualche sensibilità per l'immediatezza processuale? Ecco come rispondevano al quesito due autorevoli penalisti meridionali considerati - come si vedrà - precursori ‘italiani’ del principio di oralità.

Francesco Mario Pagano spiegava perché l'imperatore Adriano avesse vietato [D. 22.5.3] di dar fede alle testimonianze scritte nei processi criminali: «La ragione si è che la scrittura, come ben dice Socrate presso Platone, è morta [...], non ci presenta gl'infiniti possibili aspetti della cosa medesima. Nella viva voce parla eziandio il volto, gli occhi, il colore, il movimento, il tuono della voce, il modo di dire e tant'altre diverse picciole circostanze» che modificano il senso dei vocaboli. «La muta lingua, l'eloquenza del corpo» risultavano per il giudice - secondo la lezione di Cicerone - «piú veridiche delle parole» ${ }^{31}$.

«Ho udito dire», raccontava con fastidio, nel 1831, Niccola Nicolini, «che la pubblica discussione delle pruove ne' giudizii penali», effettuata in contraddittorio tra testimoni e reo, «sia un metodo diametralmente contrario alle nostre antiche leggi, e vano ove non si faccia il giudizio per

avrebbe dovuto de mandato iudicis registrarne per iscritto la vacillatio, la trepidazione, il mutamento di colorito; una prassi che inquietava CHIOVENDA, Giuseppe. L'oralità e la prova. Rivista di diritto processuale civile, v. 1, n. 1, 1924, p. 5-32; poi col tit. Sul rapporto tra le forme del procedimento e la funzione della prova (L'oralità e la prova). In CHIOVENDA, Giuseppe. Saggi di diritto processuale civile (1900-1930). Nuova edizione considerevolmente aumentata dei "Saggi" e dei "Nuovi saggi". Volume secondo. Roma: Società Editrice «Foro Italiano», 1931 [rist. anast. Milano: Giuffrè, 1993], p. 219, nt. 1. Sulla perspicuità psicologica dei giudici penali d'antico regime v. GARLATI, Loredana. Miti inquisitori: la confessione tra ricerca della verità e 'garanzie' processuali. In LUPÀRIA, Luca; MARAFIOTI, Luca (a cura di). Confessione, liturgie della verità e macchine sanzionatorie. Scritti raccolti in occasione del Seminario di studio sulle 'Lezioni di Lovanio' di Michel Foucault. Torino: Giappichelli, 2015, p. 77.

31 PAGANO, Francesco Mario. Considerazioni sul processo criminale, a cura di Filippo Maria Paladini. Prefazione di Vincenzo Ferrone. Venezia: Centro di Studi sull'Illuminismo europeo “G. Stiffoni”, 2009, cap. xxI, p. 89-90. 
giurati». L'Autore negava la fondatezza di questa ricostruzione. A suo parere, il dibattimento nel Mezzogiorno d'Italia era stato sempre pubblico; che esso fosse condotto «sul processo scritto, e non in presenza dell'accusato, ma del suo difensore, uso fu questo non patrio, ma contro le patrie leggi, non ratione, sed a barbaris introductum». Poco oltre, in un paragrafo nel quale si dichiarava risolutamente ostile alla giuria, Nicolini rammentava che «i romani imperatori credettero contrario ad ogni uso civile, anzi incompatibile co' primi e piú naturali dritti di ogni uomo, il condannare alcuno sopra un processo compilato fra altri, e con pruove raccolte senza di lui»: una «regola di ragion civile e di ragion naturale», ricavabile per traslato dalla costituzione Inter alios di Diocleziano (C. 7.60.1), impediva che un'istruzione «compilata senza intelligenza dell'accusato» potesse recargli pregiudizio se non «reiterata in di lui presenza»; e il diritto tardoantico aveva statuito analogamente l'inefficacia della testimonianza «se non citato il reo ad udirla di presenza». In un breve excursus storico Nicolini metteva in fila la sostanziale disapplicazione medievale del «principio» romanistico; la lungimirante ordinanza militare (22 maggio 1789) di Ferdinando IV, che aveva promosso il «dialogo» in dibattimento tra reo e testimone; l'«utile esperimento» delle leggi francesi (1806) e finalmente l'approdo al borbonico Codice per lo Regno, che aveva reso «essenza» del dibattimento la discussione delle prove alla presenza di giudici e parti ${ }^{32}$.

Sulla codificazione napoletana ci si soffermerà tra poco (infra, § 3 ). Per ora basti osservare che Pagano e Nicolini, accomunati da un finissimo, neo-umanistico, 'vichiano' storicismo ${ }^{33}$, collocavano nella tradizione

32 NICOLINI, Niccola. Della procedura penale nel Regno delle Due Sicilie [...]. Parte terza Vol. II. Napoli: Dalla Stamperia di M. Criscuolo, 1831, § 914, p. 327 (difesa del diritto patrio); ivi, § 915, p. 329 (obbligo romanistico di contestazione); ivi, §§ 916-918, p. 330, 332-333 (excursus).

33 AJELLO, Raffaele. I Saggi politici di Mario Pagano e il loro tempo. Il Pensiero politico, v. 28, n. 1, 1995, p. 17-57; BIROCCHI, Italo. In margine all'opera di Niccola Nicolini. Spunti per un manuale di storia giuridica dell'Ottocento. In: Tra diritto e storia. Studi in onore di Luigi Berlinguer promossi dalle Università di Siena e di Sassari. Soveria Mannelli: Rubbettino, 2008, I, p. 130-137; LUONGO, Dario. La «nuova legislazione» e l'eredità dell'antico regime: percezioni storiografiche nella cultura giuridica meridionale dell'Ottocento. In: MASTROBERTI, Francesco; MASIELLO, Gaia (a cura di). Il Codice per lo Regno delle Due Sicilie. Elaborazione, applicazione e dimensione europea del modello codicistico borbonico. Napoli: Editoriale Scientifica, 2020, p. 327-342. 
romanistica la radice profonda dell'oralità e la configuravano come immediatezza probatoria. Pagano, in particolare, auspicava che a quelle radici antiche si facesse ritorno, e che in dibattimento si esaminassero ex integro i testimoni già interrogati, le parti si confrontassero, si decidesse entro tre giorni dalla discussione. Tra i correttivi al processo vigente, egli proponeva di sostituire, ove possibile, la presentazione diretta delle parti alla lettura - di solito pregiudizievole per l'accusato - dell'informo fiscale scritto. Il giurista di Brienza, futuro martire del 1799, teorizzava anche la concentrazione: «Esame, costituto, contestazione di lite, dazion di termine facciasi nel tempo stesso e con un sol atto», senza, però, accorciare ad ogni costo i tempi dei processi per delitti atrocis ${ }^{34}$.

\section{LiVRE de LA NATURE E Vólti SENZA MASCHERA: Bentham e Nicolini}

Il Code d'instruction criminelle del 1808, coronando la transizione del processo penale francese verso il modello 'misto', stabiliva che i testimoni deponessero oralmente (art. $317^{2}$ ), ma non riproduceva il divieto, esplicito nel Code Merlin, di leggere ai giurati le deposizioni testimoniali: forse un'involontaria omissione, della quale la giurisprudenza approfittò per ampliare le deroghe all'oralità ${ }^{35}$.

La disciplina napoleonica, archetipo di numerosi ordinamenti processuali europei, non sradicò prassi consolidate. Nel Traité des preuves judiciaires (1823) Jeremy Bentham constatava come «in molti paesi», inclusa la Gran Bretagna (corte ecclesiastica e corte dell'ammiragliato), l'audizione dei testimoni e la raccolta delle prove fossero spesso affidate a giudici commissari che le trasmettevano «per iscritto» a magistrati

34 PAGANO, Francesco Mario. Considerazioni sul processo criminale, a cura di Filippo Maria Paladini. Prefazione di Vincenzo Ferrone. Venezia: Centro di Studi sull'Illuminismo europeo "G. Stiffoni”, 2009, cap. XXXIII, p. 118 e 120.

35 Cosí FERRUA, Paolo. Oralità del giudizio e letture di deposizioni testimoniali. Milano: Giuffrè, 1981, pp. 61-62. D’accordo con Hélie, criticava queste scelte MITTERMAIER, Carl Joseph Anton. Il processo orale accusatorio e per giurati secondo le varie legislazioni [...]. Versione dal tedesco dell'avv. M.M. con aggiunte. Volume unico. Reggio: Stefano Calderini e Comp. - Modena: Nicola Zanichelli e Comp., 1851, § XXIII, p. 366-367. 
sovraordinati: un malcostume che non solo ingenerava inconvenienti pratici, ma soprattutto chiudeva il livre de la nature agli occhi del giudice e lo privava dell'osservazione di «quei caratteri di verità tanto naturali e convincenti, che si riferiscono alla fisionomia, alla fermezza, alla prontezza, alle emozioni del timore, alla semplicità dell'innocenza, all'imbarazzo della mala fede». Dietro il vezzo dei giudici di delegare la raccolta delle prove, il filosofo londinese - non si sa se con ironia, come supponeva il traduttore italiano - ipotizzava che agisse «una falsa idea di dignità, od un pendío naturale a risparmiarsi la parte la piú penosa e la meno brillante del travaglio»: il giudice che cedeva a terzi l'onere di istruire si risparmiava contatti con figure, come i testimoni, per lo piú «ignoranti e zotiche», e godeva del «piú piacevole» privilegio di acquisire le testimonianze scritte e commentate da avvocati, «uomini puliti ed educati, che tolgono le spine, e facilitano gli affari» ${ }^{36}$.

Di queste pagine rimase memoria nella processual-civilistica italiana. Chiovenda ne segnalava la singolare coincidenza con le idee di Pagano. E plaudiva altresí all'art. 1 del progetto benthamiano di procédure naturelle, il quale prevedeva l'obbligo dell'incontro face à face tra le parti, en présence du juge: norma che, se fosse divenuta legge positiva, avrebbe finalmente consacrato quel principio d'immediatezza sconosciuto alla procédure technique ${ }^{37}$. Poco toglie alla suggestione di questa citazione il fatto che essa fosse desunta da De l'organisation judiciaire et de la

36 BENTHAM, Jeremy. Traité des preuves judiciaires (1823), tr. it. Teoria delle prove giudiziarie [...]. Prima versione italiana del dottore Barnaba Vincenzo Zambelli. Brusselles: Tipografia della Società Belgica, 1842, lb. III, cap. V, pp. 104-106 e 109. Lo stesso Autore, nel raccomandare una scrupolosa verbalizzazione dei processi civili e penali, suggeriva (con riferimento sia alla fase 'segreta' sia a quella 'pubblica') di trascrivere «non solamente i discorsi» ma anche gli «incidenti caratteristici, come i gesti, le esclamazioni, la lentezza affettata in rispondere, e tutti gli altri sintomi» che permettevano di giudicare i testimoni e le parti: ivi, cap. XIII, p. 123 (brano ripreso da LESSONA, Carlo. Teoria delle prove nel diritto giudiziario civile italiano [...]. Vol. IV. Seconda edizione interamente riveduta. Firenze: Cammelli, 1908, n. 339, p. 428).

CHIOVENDA, Giuseppe. L'oralità e la prova. Rivista di diritto processuale civile, v. 1, n. 1, 1924, p. 5-32; poi col tit. Sul rapporto tra le forme del procedimento e la funzione della prova (L'oralità e la prova). In CHIOVENDA, Giuseppe. Saggi di diritto processuale civile (1900-1930). Nuova edizione considerevolmente aumentata dei "Saggi" e dei "Nuovi saggi". Volume secondo. Roma: Società Editrice «Foro Italiano», 1931 [rist. anast. Milano: Giuffrè, 
codification (1823), rielaborazione, ad opera di Étienne Dumont, di appunti dell'intellettuale britannico risalenti alla stagione rivoluzionaria (1790) e all'utopia d'un rito integralmente giusnaturalistico ${ }^{38}$. D'altronde il pianeta di common law di primo Ottocento offriva ai fautori dell'oralità preziosi riscontri ${ }^{39}$.

Un altro anello della medesima catena 'genealogica' era individuato da Chiovenda in Niccola Nicolini, tra i capiscuola della penalistica italiana della Restaurazione e componente della commissione che redasse la Parte quarta del napoletano Codice per lo Regno (Leggi della procedura ne' giudizj penali, 1819). Il codice borbonico evocava, sin dal lessico, il valore dell'immediatezza. Ad esempio, l'art. 259 stabiliva che il presidente, durante la «pubblica discussione», dovesse porre «sotto gli occhi dell'accusato e del suo difensore» eventuali documenti o scritture. Ancor piú pregnante, l'art. 251 vietava, a pena di nullità, la lettura di qualsiasi «attestazione o dichiarazione scritta» (dunque, non delle sole deposizioni scritte, come avrebbe previsto l'omologo art. 311 del c.p.p. 1865 per il Regno d'Italia) di testimoni non presentatisi in udienza ${ }^{40}$, salvo, però, due ordini di

1993], p. 220-222. L'Autore si rammaricava che il processo civile italiano non avesse ancora assimilato la lezione benthamiana.

DENTI, Vittorio. Chiovenda e le riforme del processo civile. Il Foro Italiano, v. 111, n. 5, 1988, coll. 348-349. Per ulteriori considerazioni sullo squilibrio, lamentato da Bentham, tra parol evidence e written o documentary evidence v. CAPPELLETTI, Mauro. Processo orale e processo scritto nel mondo contemporaneo (1970). In: CAPPELLETTI, Mauro. Giustizia e società. Milano: Edizioni di Comunità, 1972 [rist. 1977], p. 198-199.

Come segnalato da CAPPELLETTI, Mauro. Le grandi tendenze evolutive del processo civile nel diritto comparato. Giurisprudenza Italiana, v. 120, n. 4, 1968, coll. 1-48; ora in: CAPPELLETTI, Mauro, Processo e ideologie. Bologna: il Mulino, 1969, p. 237, il giurista britannico JOHNES, Arthur James. Suggestions for a Reform of the Court of Chancery, by a Union of the Jurisdictions of Equity and Law: with a Plan of a New Tribunal for Cases of Lunacy. London: Saunders and Benning, 1834, p. 90, influenzato da Bentham e propugnatore della fusione delle corti di Law ed Equity, deplorava che nella Court of Chancery il testimone venisse interrogato solo per iscritto, circostanza che gli concedeva il tempo necessario a fabbricare una reply falsa o fraudolenta. Bill and answer, concludeva Johnes, erano non solo piú costosi ma anche meno efficienti della testimonianza orale nella ricerca della verità. 
eccezioni: l'eventuale consenso alla lettura prestato da p.m. e accusato $\left(\right.$ art. $\left.251^{2}\right)$; talune condizioni soggettive del singolo teste, e in particolare una peculiarità, questa, del codice napoletano - il fatto che il testimone (o perito) cd. generico avesse deposto in istruttoria, sotto giuramento, riguardo a reperti o esperimenti di fatto (art. 246). Quanto ai testi presenti in udienza, era vietato (art. 251) leggerne le deposizioni rese in istruttoria; il divieto veniva meno (art. 251 ${ }^{3}$ ) qualora esse contenessero, al confronto con la deposizione dibattimentale, contraddizione, variazione o differenza, tali da indurre il presidente a richiamare la discrasia alla memoria del testimone.

Nella sua opera piú celebre, Della procedura penale, e precisamente nella sezione sui Principii fondamentali della diffinitiva discussione delle pruove, Nicolini, dopo aver rammentato il vero fine della solennità e pubblicità dei giudizi (rendere visibile al processato, alla comunità e agli stessi giudici la maestà e la dignità del giudicare), asseriva che «l'essenza» del dibattimento consisteva «nel ricever» le prove «da' loro fonti originali», nel mettere i reperti «sotto gli occhi» degli astanti, nel «leggere in pubblico i documenti, udire i testimoni, confrontarli fra loro, e dibatterli in presenza con la parte pubblica, la parte civile e la parte accusata». Quanto ai tempi, poiché la sentenza doveva «esprimere l'impressione» prodotta «sull'animo de' giudici» dalla «pubblica discussion delle pruove», il dibattimento andava svolto in forma «rapida» e non «distratta», possibilmente in un solo giorno o comunque in termini tali da conservare «viva sí fatta impressione ${ }^{41}$. L'eco della lezione di Pagano risuonava inconfondibile.

All'inaugurazione dell'anno giudiziario 1833 presso la Corte Suprema di Giustizia di Napoli, Nicolini, nella veste di avvocato generale, ritornava sui plurimi pregi della «pubblica discussione». Essa permetteva

41 NICOLINI, Niccola. Della procedura penale nel Regno delle Due Sicilie [...] Parte terza Vol. II. Napoli: Dalla Stamperia di M. Criscuolo, 1831, § 860, p. 283-286. Ivi, § 870, p. 292 l'Autore ribadiva che dalla «discussione delle pruove» il giudice non potesse mai allontanarsi. Le tesi nicoliniane sull'oralità, ad avviso di CHIOVENDA, Giuseppe. L'oralità e la prova. Rivista di diritto processuale civile, v. 1, n. 1, 1924, p. 5-32; poi col tit. Sul rapporto tra le forme del procedimento e la funzione della prova (L'oralità e la prova). In: CHIOVENDA, Giuseppe. Saggi di diritto processuale civile (1900-1930). Nuova edizione considerevolmente aumentata dei "Saggi" e dei "Nuovi saggi". Volume secondo. Roma: Società Editrice «Foro Italiano», 1931 [rist. anast. Milano: Giuffrè, 1993], p. 220, erano state giustamente apprezzate da Mittermaier. 
di non fermarsi «alla prima sopraffaccia» del processo; di apprendere le informazioni dalla diretta «voce» dei testimoni; di scovare il teste mendace, perché «il pubblico con la sua tacita disapprovazione avvert[iva] i giudici, e lo confonde[va]». L'udienza, «fra mille contrapposizioni e confronti, dal volto, dal gesto, dagli atti, non pur de' testimoni, ma di tutti gli astanti», proiettava sulla vicenda «un tal contrasto, un tal riverbero di lumi, che malgrado le astuzie della calunnia, e la caligine de' sofismi, ed i prestigi dell'eloquenza», alla fine la verità traluceva, anzi sfolgorava. Nello «spettacolo di una pubblica discussione» il colpevole «inavvedutamente» si rivelava; «gli si legge[va] in viso il tardo pentimento, e le ire impotenti, e le speranze ingannevoli [...]; ad ogni testimonianza, ad ogni parola, ad ogni cenno che colpi[va] il reo» l'osservatore esterno vedeva «cader di volto la maschera». Infine il dibattimento dava modo al governo di conoscere il «territorio, e scrutinarne il costume», di conoscere «lo stato ed i bisogni del suo popolo: questa è la piú potente, la piú efficace scuola di pubblica morale» ${ }^{42}$.

Il discorso del 1833, come può notarsi, agganciava il beneficio dell'immediatezza non tanto ai tecnicismi delle regole sulle letture dibattimentali quanto alla compartecipazione 'appassionata' del pubblico: era questo quid politico, scenico, che prometteva di rendere il processo sincero, spontaneo, decifrabile, senza filtri. A chi paventava il «flagello de' testimoni» che, in udienza, si scostavano «di qualche linea dal processo scritto» e cosí trasformavano il giudizio in «satira de' giudici istruttori» Nicolini ribaltava la prospettiva: il dibattimento, a suo dire, avrebbe potuto correggere gli errori della prima fase proprio perché esso era «animato», «originale», sprigionava «spiegazioni pronte, confrontazioni presenti, e dalla forza del dialogo quell'impronta di vita, quella forza di evidenza, che sfugge sempre a chi, quasi schiavo alla catena, incapace a veder nulla da sé, giura sull'altrui detto, e perduta ogni vitalità di mente, alle mute e morte carte si attiene» ${ }^{43}$.

42 NICOLINI, Niccola. Della discussione pubblica ne' giudizii penali. Discorso pronunziato alla Corte Suprema di Giustizia di Napoli a camere riunite [...] nel dí 7 gennaio 1833 [...]. Napoli: Dalla Stamperia Salita Infrascata, ,1833, n. 344, p. 16-19.

${ }^{43}$ NICOLINI, Niccola. Della discussione pubblica ne' giudizii penali. Discorso pronunziato alla Corte Suprema di Giustizia di Napoli a camere riunite [...] nel dí 


\section{LEZIONI DALL'EUROPA: IMPRESSION E UNMITTELBARKEIT}

Nei decenni centrali del secolo XIX la processual-penalistica europea di fede liberale diffondeva fiducia nelle potenzialità impressionistiche del giudizio, purché questo fosse strutturato in modo da agevolare il diretto contatto del giudice con la prova obiettiva. L'esigenza era particolarmente avvertita negli ordinamenti giudiziari che contemplavano la giuria. Quest'ultima, notava per esempio Faustin Hélie, non era attrezzata a formarsi un'opinione mediante la lettura degli atti: occorreva, invece, metterla al cospetto dei fatti («il faut le placer en présence des faits»), vale a dire delle testimonianze, e domandarle quale impression quei fatti le avessero procurato ${ }^{44}$.

Sull'altra sponda del Reno Carl Joseph Anton Mittermaier, nel paragrafo sull'Oralità contenuto nel testo-bandiera Il processo orale accusatorio e per giurati (1845), premetteva che «tutte le odierne legislazioni di procedura penale» elevavano a «principio fondamentale» l'obbligo, per accusato e testimoni, di comparire «al cospetto dei giudici chiamati a conoscere» e, per i giudici, di pronunciare la sentenza «solo in base alla discussione orale». Addentrandosi nei contenuti dell'oralità, egli la prospettava essenzialmente come Unmittelbarkeit: parola resa dal traduttore italiano con la circonlocuzione «mezzo di vedere le cose con un unico sguardo». Per il giurista bavarese una procedura poteva definirsi orale quando: 1) l'accusato comparisse personalmente davanti ai giudici e contribuisse a «rilevare le prove» e a difendersi; 2) i giudici vedessero e «personalmente ascolt[asser]o tutti i testimoni e gli esperti» e 3) fossero messi in grado di «convenientemente rimuovere ogni dubbio interrogando[li]»; 4) il giudizio fosse «pronunciato unicamente in base alle deduzioni verbali dell'accusatore, dell'accusato o del suo

7 gennaio 1833 [...]. Napoli: Dalla Stamperia Salita Infrascata, 1833, n. 344, p. 21-22. NICOLINI, Niccola. Quistioni di dritto trattate nelle conclusioni, ne' discorsi ed in altri scritti legali [...]. Vol. I. Napoli: Dalla Tipografia Salita Infrascata, 1835, p. 146-149 avrebbe confermato l'opzione per un dibattimento quale momento di serrato dialogo tra le parti e di diretta e condivisa disamina delle prove.

44 HÉLIE, Faustin, Traité de l'instruction criminelle ou Théorie du code d'instruction criminelle [...]. Deuxième édition entièrement revue et considérablement augmentée. Tome premier. Paris: Henri Plon, 1867, § 2034, p. 50. 
difensore». Lo studioso tedesco reputava a tal punto assorbenti le suddette coordinate - il cui comune denominatore, a ben guardare, consisteva in un'ideale prossimità tra giudice e prove - da etichettare come «procedura penale» solo il dibattimento orale, mentre l'eventuale fase «di preparamento» non era «essenziale» ${ }^{45}$.

Dei «vantaggi decisivi» del processo orale, minuziosamente elencati da Mittermaier, alcuni si sostanziavano proprio nella Unmittelbarkeit. A suo avviso, ad esempio, l'oralità forniva la «certezza» che i giudici conoscessero «fedelmente, per intero e nella loro vera connessione le deposizioni dell'accusato e dei testimonii»: perché - si chiedeva l'Autore - non approfittare di questa Unmittelbarkeit (nella traduzione italiana: «discuter le cause e sentir le persone sulle cui deposizioni vuolsi fondare il giudizio»), anziché attingere a deposizioni de relato? E ancora: l'oralità consentiva di valutare l'«individualità degli accusati e dei testimoni», di misurare con uno «sguardo» l'imputabilità dei primi e di dedurre la «credibilità» dei secondi dalla loro «serietà»o «leggerezza», dal «continuo vacillare e simili»; la sequenza ininterrotta delle deposizioni e «il rapido concatenarsi delle prove», specie di quelle indiziarie, animavano «incessantemente l'attività intellettuale dei giudici» e trasmettevano loro un'«immagine» d'insieme ${ }^{46}$.

45 MITTERMAIER, Carl Joseph Anton. Il processo orale accusatorio e per giurati secondo le varie legislazioni [...]. Versione dal tedesco dell'avv. M.M. con aggiunte. Volume unico. Reggio: Stefano Calderini e Comp. - Modena: Nicola Zanichelli e Comp., 1851, § xxıII, p. 334 e 336. Per il testo tedesco originale v. MITTERMAIER, Carl Joseph Anton. Die Mündlichkeit, das Anklageprincip, die Oeffentlichkeit und das Geschwornengericht. Stuttgart und Tübingen: Cotta, 1845, § XXII, p. 246.

MITTERMAIER, Carl Joseph Anton. Il processo orale accusatorio e per giurati secondo le varie legislazioni [...]. Versione dal tedesco dell'avv. M.M. con aggiunte. Volume unico. Reggio: Stefano Calderini e Comp. - Modena: Nicola Zanichelli e Comp., 1851, § XXIII, p. 338 (vantaggi), 341-343 (individualità), 346-347 (indizi). Per la corrispondenza nel testo tedesco v. MITTERMAIER, Carl Joseph Anton. Die Mündlichkeit, das Anklageprincip, die Oeffentlichkeit und das Geschwornengericht. Stuttgart und Tübingen: Cotta, 1845, § XXII, p. 248 (vantaggi). Da notare che, nelle pagine dedicate alla riforma della procedura penale negli Stati di Brunswick, MITTERMAIER, Il processo orale accusatorio, § xx, p. 275 citava una relazione del presidente Steinacker (1843) secondo cui l'adozione del giudizio orale avrebbe permesso di acquisire «una perfetta cognizione degli elementi probatorii»: il risultato, ad avviso del 
Lealmente Mittermaier non passava «sotto silenzio» le obiezioni all'oralità. Alcune di queste nascevano dal timore che un eccesso, per cosí dire, d'immediatezza (la gradevolezza o la rozzezza di un imputato, i suoi «gesti», «il facile sbigottimento e l'imbarazzo de' testimoni») sviasse l'attenzione del giudice. Pur senza sottovalutare le incognite, il professore di Heidelberg però confidava, da un lato, che l'eventuale «impostura e la dissimulazione» si sarebbero ritorte contro l'imputato, dall'altro che almeno il giudice togato (se non, forse, il giurato) sapesse correttamente soppesare «le prove che gli stanno dinanzi». Quanto al teste, Mittermaier raccomandava di trattarlo «con decoro ed amorevolezza». Anzi, egli deprecava sia l'aggressività di certi pubblici ministeri verso testimoni che non rispondevano secondo le attese, sia le altrettanto frequenti domande «sconvenienti e vergognose» formulate dal difensore ${ }^{47}$.

\section{IL PRIMO CODICE ITALIANO: «TROPPE ECCEZIONI»}

Le pennellate di Mittermaier sulla Unmittelbarkeit incuriosirono la dottrina italiana post-unitaria, la quale tuttavia, almeno inizialmente, era calamitata dall'esegesi piú che dalla sistemazione concettuale. Il codice di procedura penale per il Regno d'Italia (1865), rimaneggiamento del testo sabaudo del 1859 e dunque largamente esemplato sul calco del code d'instruction criminelle, sanciva la regola dell'oralità sia a proposito dell'ordine di discussione, laddove stabiliva (art. 281, n. 3) che testimoni e periti andassero sentiti; sia obbligando costoro a deporre «oralmente, sotto pena di nullità» (artt. 304 e 310), salvo la possibilità (art. 304²) di servirsi di note e memorie. In udienza era vietato leggere le «deposizioni scritte dei testimoni» presenti (art. 311), a meno che non bisognasse «far risultare de' cangiamenti o delle variazioni» intervenuti nella deposizione

relatore, sarebbe stato conseguito «per mezzo del dibattimento immediato [nell'ed. originale: durch die Unmittelbarkeit] e dello sviluppo completo della prova, collo scorgere ed udire personalmente l'accusato» (per l'ed. tedesca v. MITTERMAIER, Die Mündlichkeit, § xx, p. 194).

47 MITTERMAIER, Carl Joseph Anton. Il processo orale accusatorio e per giurati secondo le varie legislazioni [...]. Versione dal tedesco dell'avv. M.M. con aggiunte. Volume unico. Reggio: Stefano Calderini e Comp. - Modena: Nicola Zanichelli e Comp., 1851, § XXIII, p. 352-356. 
orale (art. $311^{2}$ ). Quanto ai testi citati ma non comparsi, il consenso tra le parti rendeva lecita la lettura delle relative deposizioni, «a titolo di semplici indicazioni e schiarimenti» (art. $311^{3}$ ). In linea generale, era permesso leggere verbali e rapporti «relativi alla causa» (art. 281 n. 2) e discutere in dibattimento «i documenti e gli oggetti» potenzialmente utilizzabili «a convinzione o a discolpa» (art. 287 n. 7). Restava, infine, in agguato il rischio - energicamente sventato, viceversa, dal napoletano Codice per lo Regno ${ }^{48}$ - che nel segreto della camera di consiglio i giudici sfogliassero il fascicolo comprensivo delle deposizioni testimoniali: prassi che avrebbe frustrato l'oralità e dissolto le «impressioni» sonore e visive acquisite durante il dibattimento ${ }^{49}$.

Non è difficile cogliere in questo reticolo normativo, peraltro punteggiato da vaghezze terminologiche, numerose smagliature: il codice, come appariva palese ai tanti denigratori, contemplava «troppe eccezioni» al divieto di lettura in udienza, le quali insidiavano la «sincerità del giudizio» e ne compromettevano «l'autonomia» consentendo «ingerenze» istruttorie $^{50}$. La giurisprudenza ci aggiungeva del suo. La Cassazione romana riteneva non censurabile il comportamento dei giudici che avessero

48 NICOLINI, Niccola. Della procedura penale nel Regno delle Due Sicilie [...]. Parte terza Vol. II. Napoli: Dalla Stamperia di M. Criscuolo, 1831, § 1104, p. 460 ricordava che in camera di consiglio i giudici erano autorizzati a consultare soltanto il verbale d'udienza redatto dal cancelliere (art. 267). Questo verbale, spiegava l'Autore, andava firmato, non a caso, prima di deliberare: «La instruzione scritta», benché «necessaria»e «utile a preparar l'accusa ed il dibattimento, dee sparire a' loro occhi [n.d.r.: dei giudici], quando si entra a deliberar sulla causa», con la sola eccezione, per l'appunto, del verbale di dibattimento.

BORSANI, Giuseppe; CASORATI, Luigi. Codice di procedura penale italiano commentato [...]. Libro secondo [...]. Volume quarto. Milano: Giacomo Pirola, $1879, \S 1385$, p. 155.

LUCCHINI, Luigi. Elementi di procedura penale. Firenze: Barbèra, 1895, n. 285, p. 311; LUCCHINI, Luigi. Elementi di procedura penale. Seconda edizione riveduta e ampliata. Firenze: Barbèra, 1899, n. 285, p. 317-318; LUCCHINI, Luigi. Elementi di procedura penale. Terza edizione riveduta e ampliata. Firenze: Barbèra, 1905, n. 285, p. 319, con riguardo ai cangiamenti di cui all'art. $311^{2}$ c.p.p. 1865 . Al contrario, BORSANI, Giuseppe; CASORATI, Luigi. Codice di procedura penale italiano commentato [...]. Libro secondo [...]. Volume quarto. Milano: Giacomo Pirola, 1879, § 1364, p. 124 ritenevano che quest'ultima norma valorizzasse la funzione 'critica' del vaglio dibattimentale. Essi però (ivi, § 1353, p. 100), anche con il conforto della giurisprudenza francese, 
letto la deposizione istruttoria dopo che il testimone aveva dichiarato di non ricordare piú nulla e aveva rimandato a quanto riferito in avvio del procedimento ${ }^{51}$.

Insomma, «nonostante taluni progressi» rispetto ai codici sardi e al code del 1808, il primo codice di rito del Regno d'Italia restava lontano «dal realizzare quella immediatezza» tra giudice e fonti di prova tipica del modello anglosassone e delle prime leggi rivoluzionarie. Del resto il modello misto 'all'italiana', che rimetteva al giudice istruttore e poi alla camera di consiglio o alla sezione d'accusa un plurimo vaglio del materiale probatorio, impediva al giudice della decisione - specie se togato - di sbarazzarsi con disinvoltura di prove ripetutamente filtrate da colleghi ${ }^{52}$.

Lo si arguisce da un lucido saggio del 1876 di Erio Sala, professore all'Università di Modena. Il testo affrontava, per la verità, un tema alquanto diverso: la preclusione frapposta dal codice del 1865 all'intervento del difensore in istruttoria. Però l'articolo merita qui una menzione perché segnalava non solo l'utilità dell'immediatezza già nella prima fase del processo (dove dal «contegno dell'imputato» l'istruttore avrebbe avuto l'opportunità di cogliere «un'aura che non si imita, che non si rivela, e non si comunica, che si sente e non si definisce»), ma anche l'irrimediabilità di eventuali calunnie patite in quella sede dall'inquisito. Non a caso si assisteva spesso in giudizio a «scene scandalose»: se il teste rendeva dichiarazioni difformi da quelle istruttorie, il giudice, spalleggiato da «Giurati e popolo», si alterava, «grida[va] alla intangibilità della persona del giudice istruttore»; il testimone, spaventato, dichiarava «miseramente» di non ricordare con precisione ma d'aver detto la verità; «tutti s'acquieta[va]no» all'illogica risposta e s'illudevano che la giustizia trionfasse; il presidente s'«inorgogli[va] della sua abilità». Perciò, concludeva Sala, «gli errori del processo scritto» erano «fatali anche nel processo pubblico»: e quest'ultimo non costituiva quella «solenne guarentigia» della quale si

contrastavano le forzature all'art. $304^{2}$ c.p.p. 1865 , che permetteva ai testimoni di servirsi, in udienza, di note e memorie.

51 BORSANI, Giuseppe; CASORATI, Luigi. Codice di procedura penale italiano commentato [...]. Libro secondo [...]. Volume quarto. Milano: Giacomo Pirola, 1879, § 1365, p. 126-129.

52 FERRUA, Paolo. Oralità del giudizio e letture di deposizioni testimoniali. Milano: Giuffrè, 1981, p. 104-107. 
parlava «con tanta pomposità». Per prevenire «sconci» non restava che dischiudere all'imputato le porte dell'istruzione ${ }^{53}$.

D'altronde, era proprio nello stadio iniziale che il processo accumulava quella ingestibile mole cartacea destinata a piombare sul dibattimento. In una circolare del 1880 che si prefiggeva d'incentivare il ricorso all'istruzione sommaria il guardasigilli Tommaso Villa deplorava l'abitudine di assumere, nella citazione diretta, una sovrabbondanza di testimonianze scritte, ricadendo cosí «nelle lungaggini» dell'istruttoria formale. Un simile atteggiamento, ammoniva il ministro, andava «precisamente contro lo spirito del processo immediato, di portare cioè innanzi al giudice del merito, senza indugi e spoglie d'ogni artificiale elaborazione, le prove [...] per sostituire le vive e schiette impressioni del metodo orale a quelle malsicure degli atti scritti» ${ }^{54}$.

\section{IL DIVARIO TRA PRINCÍPI E NORME: LA PROCESSUAL-PENALISTICA 'MODERATA'}

Nonostante le non lievi incongruenze nel codice del 1865, il piú diffuso commentario, a firma di Giuseppe Borsani e Luigi Casorati, salutava nell'oralità «uno de' principi fondamentali dell'odierno processo penale», un propulsore della «giustizia punitrice» grazie allo «strettissimo rapporto» con l'intimo convincimento. I due autori erano espressione di quell'ala moderata della processual-penalistica liberale abituata a muoversi tra proclami ideali e leggi inadeguate. Nello specifico, essi ritenevano che il canone in questione, pur non implicando la proscrizione di qualsiasi

53 SALA, Erio. Dell'intervento dell'imputato nella istruzione del processo penale. Rivista Penale, vol. V, fsc. ago., 1876, p. 14-15, 19-20.

54 VILLA, Tommaso. Circolare (n. 868) del Ministero di Grazia e Giustizia e dei Culti, 25 gennaio 1880. Vantaggi derivanti dalla citazione diretta nei procedimenti penali. In Collezione celerifera delle leggi, decreti, istruzioni e circolari dell'anno 1880 ed anteriori, LIX. Roma: Presso gli Editori, via S. Uffizio 1, 1880, p. 370. Cfr. STORTI STORCHI, Claudia. Difetti del sistema e difetti d'uomini. Citazione diretta e logica dell'istruzione dal codice di procedura penale del 1865 alle soglie della pubblicazione del codice del 1913. In: MILETTI, Marco Nicola (a cura di). Riti, tecniche, interessi. Il processo penale tra Otto e Novecento. Atti del convegno (Foggia, 5-6 maggio 2005). Milano: Giuffrè, 2006, p. 241. 
scrittura, impegnasse il giudice a decidere sulla base dell'«esame immediato delle prove» raccolte in dibattimento (in modo da evitare l'intermediazione «dei sensi altrui»), anziché sul «procedimento scritto». In virtú dell'oralità, proseguivano i due studiosi, i giudici vedevano «svolgersi in loro presenza tutte le prove», non solo grazie al «conflitto delle deposizioni» ma anche per «il contegno dei testimoni e dell'accusato, per le emozioni che provano, pei gesti e i turbamenti che svelano l'intimo loro sentire, e insieme per tutti quei segni che parlano eloquentemente agli occhi, e che non è possibile di ritrarre esattamente con le parole ${ }^{55}$.

L'accento, come si vede, ricadeva sulla superiorità emotiva, impressionistica, visiva (ancora il richiamo agli occhi) di un'oralità sovrapponibile, di fatto, all'immediatezza. Ma non esaurentesi in questa. Tra i corollari della prima Borsani e Casorati indicavano il principio di concentrazione, da loro battezzato continuità del dibattimento. La «massima» - spiegavano - mirava tra l'altro a «promuovere l'unità del contesto, vale a dire della trattazione della causa, tanto giovevole a far sí che i giudici possano abbracciare da un punto di vista complesso i risultati della medesima ${ }^{56}$. Non sfugge l'assonanza tra quest'ultima locuzione e quella (mezzo di vedere le cose con un unico sguardo: v. supra, § 4) utilizzata dal traduttore di Mittermaier per rendere in italiano Unmittelbarkeit.

Borsani e Casorati, però, ritenevano troppo permissiva la disciplina del c.p.p. 1865. Questo infatti dettava, sí, tempi contingentati (il dibattimento poteva proseguire all'udienza successiva, art. 281; al termine, la pronuncia andava resa immediatamente, art. 318), ma di fatto li imponeva soltanto alla corte d'assise (art. 510), mentre consentiva al pretore e al tribunale correzionale rinvii sino a dieci giorni «per gravi motivi e col consenso delle parti» (art. $\left.282^{2}\right)$.

55 BORSANI, Giuseppe; CASORATI, Luigi. Codice di procedura penale italiano commentato [...]. Libro secondo [...]. Volume quarto. Milano: Giacomo Pirola, 1879, § 1351, p. 96-97. Nello stesso senso cfr. ALIMENA, Bernardino. Appunti di diritto e procedura penale. Cagliari: s.t., 1898-99, p. 285: il giudice «non deve giudicare, diremo quasi sulle fotografie, ma deve vedere in faccia le persone, deve veder scorrere dinanzi a sé tutte le prove, deve sentire i testi esprimersi con la viva voce».

56 BORSANI, Giuseppe; CASORATI, Luigi. Codice di procedura penale italiano commentato [...]. Libro secondo [...]. Volume quarto. Milano: Giacomo Pirola, 1879, cap. III (sommario), p. 146; ivi, cap. III, § 1381, p. 149. 
La Relazione al codice del guardasigilli Paolo Cortese giustificava questo 'allentamento' in una logica di risparmio erariale, pur non nascondendosi la necessità di non disperdere «le impressioni ricevute ${ }^{57}$. Per questo stesso motivo, e per evitare che i giudici della decisione «vaga[ssero] tra le incertezze e le titubanze di mal sicuri ricordi», Francesco Saluto, autore del primo commentario al codice unitario di rito, riconosceva che un'accezione rigorosa di oralità avrebbe richiesto l'unicità del contesto. Tuttavia il giurista siciliano non si scandalizzava per la tolleranza accordata dal codice a preture e tribunali correzionali, dove - diversamente che in corte d'assise - sedevano giudici «non distratti da occupazioni estranee, forniti di una intelligenza superiore ad ogni altro individuo» e quindi in grado di ritenere «con maggiore vivacità i fatti» risalenti a «qualche giorno» addietro. Ad ogni modo, Saluto raccomandava di non elargire proroghe «con leggerezza» perché queste, quantunque insindacabili in Cassazione, rappresentavano altrettante «ferite» all'oralità e alla continuità dei dibattimenti ${ }^{58}$. In realtà, poi, la Suprema Corte ebbe modo di sindacare l'esercizio del potere di rinvio: un arresto del 1890, ad esempio, interpretò restrittivamente il limite cronologico di cui all'art. 282 , onde «impedire che venisse frustrato il principio dell'oralità dei dibattimenti e che la decisione del magistrato non si inspirasse alle ancor vive impressioni dell'orale discussione» ${ }^{59}$.

A differenza del collega Saluto, Borsani e Casorati reputavano «infelice» la previsione codicistica della proroga. A loro avviso, l'allungamento del dibattimento avrebbe indotto i giudici ad attingere al procedimento scritto, «in onta del principio fondamentale della oralità $»^{60}$.

57 Cfr. CORTESE, Paolo. Relazione sul codice di procedura penale. In: Codice di procedura penale del Regno d'Italia colla Relazione del ministro guardasigilli fatta a S.M. in udienza del 26 novembre 1865 [...]. Firenze: Stamperia Reale Torino: Tip. Eredi Botta, 1866, p. XIX.

58 SALUTO, Francesco. Commenti al codice di procedura penale per il Regno d'Italia [...]. Volume III. $2^{\text {a }}$ ed. Torino: Bocca, 1877, § 957, p. 167.

59 Cass. Pen., ud. 29 gennaio 1890, pres. De Cesare, rel. Barletti, p.m. Fiocca, ric. Germanà Giuseppe. Cassazione Unica, v. 1, 1889, p. 205.

60 BORSANI, Giuseppe; CASORATI, Luigi. Codice di procedura penale italiano commentato [...]. Libro secondo [...]. Volume quarto. Milano: Giacomo Pirola, $1879, \S 1383$, p. 152. 
Nessun dubbio, poi, che in corte d'assise si corresse un rischio piú elevato di scolorimento delle prove, come notava Filippo Manduca, allievo di Pessina e magistrato liberale. A causa della cronica lunghezza dei processi, incalzava lo studioso, «alla giustizia sottentra[vano] la pietà, la compassione; l'oralità scompar[iva]» perché la morte di querelanti, denuncianti, testimoni obbligava alla lettura degli atti: ma cosí arrivava ai giurati una «pallida immagine della dichiarazione orale» che li annoiava e non lasciava loro alcuna «impressione». «Da qui le assoluzioni, da qui il trionfo del delitto» ${ }^{61}$.

\section{Nella luce del meriggio: la Crociata CarRariana}

Svincolata dalla griglia codicistica e dalla cautela stilistica del commentario, la penalistica di formazione carrariana, parimenti abbeveràtasi ai tomi degli Hélie e dei Mittermaier, vedeva nell'immediatezza l'innesco d'un giudizio non piú avvolto - per citare il giovane Lucchini «nel tenebrore politico» ma celebrato «innanzi al popolo, in piena luce di meriggio, pubblicamente» ${ }^{62}$.

Il successo d'una campagna cosí ambiziosa presupponeva il taglio d'un nodo gordiano: l'affrancamento del dibattimento dalla «zavorra inquisitoria ${ }^{63}$. L'architettura a «duplice arcata» dei codici di derivazione napoleonica comportava uno schiacciamento della fase dibattimentale su quella delle indagini ${ }^{64}$. Il rito 'italiano' non era esente da questo vizio. Come lamentava Francesco Carrara, il processo scritto, formalmente null'altro che una «semplice informativa», aveva finito per fagocitare il giudizio. Da un lato la legge attribuiva «efficacia giuridica» ai verbali di ispezione o di testimonianze irripetibili. Dall'altro, per prassi, presidenti e pubblici

61 MANDUCA, Filippo. La procedura penale e la sua evoluzione scientifica. Napoli: Ernesto Anfossi, 1888, p. 178.

62 LUCCHINI, Luigi. Pubblicità oralità e contraddittorio della istruttoria del processo penale. Appunti critici [...]. Estratto dal Giornale Giuridico «La Rivista». Verona: Tipografia M. Dal Ben, 1873, p. 3.

63 LUCCHINI, Luigi. I semplicisti (antropologi, psicologi e sociologi) del diritto penale. Saggio critico. Torino: Unione Tipografico-Editrice, 1886, p. 254.

64 DEZZA, Ettore. Il primo codice di procedura penale dell'Italia unita (1865). In Codici penali. Padova-Torino: Cedam e Utet giuridica, 2011, p. XcIII. 
ministeri pretendevano, a pena di mendacio, che il testimone riproducesse alla lettera quanto dichiarato in istruzione e non osasse eccepire d'esser stato «male inteso o male scritto» nella prima fase del procedimento ${ }^{65}$.

Secondo Emilio Brusa, penalista dell'Università di Torino e allievo di Carrara, solo la giuria avrebbe potuto innalzare una vera barriera tra il circuito probatorio dell'istruzione e quello del dibattimento. Mentre, infatti, il giudice di professione era inevitabilmente incline ad accodarsi all'«operato» dei colleghi istruttori, cosí ingenerando nell'opinione pubblica il sospetto («una nube») di lasciarsi guidare «da impressioni estranee al dibattimento» e specialmente dalla «lettura di atti scritti»; la magistratura popolare rassicurava il pubblico perché «riprodu[ceva] sotto i suoi occhi con la maggior fedeltà possibile il dramma del reato». Il paragone s’inseriva in un piú ampio ragionamento che invitava ad apprezzare la spontaneità del giurí popolare e a non soppiantare del tutto, almeno nel processo penale, il «semplice senso volgare» con il «senso scientifico o tecnico» ${ }^{66}$.

A Brusa replicò, a stretto giro, Raffaele Garofalo, fondatore della scuola positiva e magistrato dalla spiccata tempra conservatrice. Garofalo contestava, tra l'altro, l'idea per cui «tutto il processo scritto, cioè a dire l'insieme delle ragioni per le quali l'accusato [era stato] sospettato e tratto alle Assise», non contasse piú nulla al momento del dibattimento e bisognasse emettere la sentenza sulla sola base delle dichiarazioni rese dinanzi ai giurati. «Con simili esagerazioni - tuonava il giurista napoletano - si dà a qualsiasi ribaldo la spada del combattente e spesso l'aureola dell'eroe», mentre in realtà già il mero rinvio a giudizio faceva scattare una «presunzione di colpabilità». Per Garofalo, in definitiva, l'intero lavoro istruttorio doveva esercitare «influenza sul giudizio», a meno di non renderlo «opera vana e tempo perduto» ${ }^{67}$.

65 CARRARA, Francesco. Il diritto penale e la procedura penale. Prolusione al corso di diritto criminale dell'a.a. 1873-74, nella R. Università di Pisa [Pisa, 12 novembre 1873]. In: CARRARA, Francesco. Programma del corso di diritto criminale. Del giudizio criminale. Con una selezione dagli Opuscoli di diritto criminale. Bologna: il Mulino, 2004, p. 434-435.

66 BRUSA, Emilio. Sul giurí, ad occasione delle recenti discussioni dei giuristi svizzeri [Torino, 20 gennaio 1882]. Rivista Penale, vol. 15, fsc. IV-V, 1882, p. 316-317, 320-321, 322-323, 327.

67 GAROFALO, Raffaele, I pericoli sociali di alcune teorie giuridiche. Archivio di Psichiatria, Scienze penali ed Antropologia criminale, v. 3, 1882, p. 389-392. 


\section{Contro IL MITO DELL'ORALITÀ: LA SFIDA POSITIVISTA}

Per contestualizzare un assunto cosí visceralmente anti-garantista è opportuno ricordare che i primi penalisti 'lombrosiani' fantasticavano d'un rinnovamento ab imis del rito vigente. Proprio Garofalo immaginava che in una procedura ripensata secondo i dettami dell'antropologia criminale una «discussione sul fatto» si sarebbe aperta solo se l'imputato avesse contestato l'accusa; mentre una altrettanto scarnificata discussione in diritto avrebbe definito il reato, classificato il relativo autore e fissato una misura appropriata alla sua temibilità. Il complessivo ridimensionamento della fase dibattimentale avrebbe, di riflesso, infranto i miti della pubblicità e dell'oralità ${ }^{6}$.

Nella monografia d'esordio I simboli (1893) Guglielmo Ferrero, eclettico intellettuale vicino a Lombroso, declassava l'oralità dibattimentale a retaggio d'una tradizione primitiva e acritica, risalente «al tempo in cui le discussioni si facevano tutte con la parola». Deformato da questa logica arcaica, il rito penale - si stupiva il giovane autore - riponeva «piú importanza alla deposizione» del teste in udienza, anziché a quella rilasciata davanti al giudice istruttore: e invece sarebbe dovuto accadere l'inverso, tenuto conto della prossimità agli eventi e della superiore credibilità d'un ambiente lontano «dal pubblico, dall'accusato, dall'apparato della giustizia» e dal connesso corredo di impressione e confusione. Quando «tra un secolo o due» - profetizzava Ferrero - la scrittura avrebbe soppiantato anche nella vita giudiziaria la testimonianza orale, i posteri si sarebbero meravigliati «che un tempo il processo fosse [stato] una cosí strana mescolanza di oralità e di scrittura; che il testimone venisse a ripetere ciò che aveva già detto ed era stato ridotto a protocollo; che infine si facesse tutta quella rappresentazione teatrale cosí costosa [...], incomoda e [...] inutile» ${ }^{69}$.

Neppure la scuola positiva, però, si esprimeva all'unisono. Enrico Ferri, che pure riportava in Sociologia sia le considerazioni di Garofalo (trascritte alla lettera) sia i pronostici di Ferrero, da avvocato di rango ammetteva che «sui giudici togati, sopraccarichi di lavoro, e perciò

68 GAROFALO, Raffaele. Criminologia. Studio sul delitto e sulla teoria della repressione [...]. $2^{\text {a }}$ ed. Torino: Bocca, 1891, p. 411-412.

69 FERRERO, Guglielmo. I simboli in rapporto alla storia e filosofia del diritto alla psicologia e alla sociologia. Torino: Bocca, 1893, p. 67-68. 
impossibilitati a fare una critica seria e profonda, il processo scritto», parimenti «abborracciato in fretta» da giudici istruttori non meno oberati, esercitava «troppo spesso un'influenza dannosa ora contro l'accusato, ora contro la società $\rangle^{70}$.

Un approccio positivista altrettanto equilibrato permeava il volumetto di Agostino Berenini (1887) sui Limiti della prova. L'Autore, professore pareggiato all'Università di Parma, si dichiarava perplesso dinanzi alla pretesa del c.p.p. 1865 di «cancellare affatto dalla [...] mente» del giudice l'«impressione» procuràtagli dalla «lettura del processo scritto». Provando a invertire il punto di vista, Berenini osservava che la fase orale avrebbe dovuto non già azzerare le risultanze istruttorie, bensí confermarle, «dissiparne le incertezze e le ambiguità, svelarne gli errori [...]. La oralità deve essere la prova del fuoco, alla quale si saggiono [sic] le risultanze scritte, e, mediante il contraddittorio, si completano»; altrimenti, se si desiderava obliterare il processo scritto per mezzo d'una «finzione legale», sarebbe stato, paradossalmente, preferibile risparmiare del tutto l'istruttoria e passare a un accusatorio integrale ${ }^{71}$.

Alcuni passaggi del libro di Berenini brillavano per pragmatismo epistemologico. Pretendere che il giudice - rifletteva l'Autore - si pronunciasse solo sulla base di quanto percepito in udienza, «mentre si sa[peva]» che al dibattimento egli non arrivava affatto «ignaro della causa»e, anzi, se n'era già formato un qualche convincimento, significava disconoscere le reali dinamiche della cognizione processuale e affidarsi piú «alla pomposità di un nome» che «alla sostanzialità di un principio» ${ }^{72}$.

Accostando l'oralità al concetto di virtuale appartenenza del potere giudiziario al popolo, il giurista parmense esortava a guardarla

70 FERRI, Enrico. Sociologia criminale. Terza edizione completamente rifatta dei Nuovi orizzonti del diritto e della procedura penale. Torino: Bocca, 1892, p. 654658 e ivi, p. 657-658, nt. 1 (ove mancava, per ovvi motivi cronologici, il cenno a Ferrero); FERRI, Enrico. Sociologia criminale. $4^{\mathrm{a}}$ ed. Torino: Bocca, 1900, p. 802-805 e ivi, p. 805, nt. 1.

71 BERENINI, Agostino. Limiti della prova in criminale. Brevi considerazioni con particolare riferimento all'articolo 848 del codice di procedura penale. Parma: Luigi Battei, 1887, p. 37-38.

72 BERENINI, Agostino. Limiti della prova in criminale. Brevi considerazioni con particolare riferimento all'articolo 848 del codice di procedura penale. Parma: Luigi Battei, 1887, p. 39. 
come strumento per chiarire, completare, fecondare il «buio del processo scritto». Essa valorizzava il «gesto», la «voce», il «cenno», il «coloramento del viso», le «reticenti interiezioni». Da qui la proposta - la tesi centrale del libro - di lasciare al libero apprezzamento del giudice la scelta sulla lettura di testimonianze, verbali, rapporti o altri documenti ritenuti utili. D'altronde non sussisteva un «divieto assoluto» di lettura: lo provava la regola (uno «strappo [...] davvero irragionevole») che permetteva di leggere in appello il verbale del giudizio di primo grado. L'idea di Berenini, «né rivoluzionari[a] né reazionari[a]» (come d'altronde si evinceva sin dal saluto iniziale al maestro Ferri), si sintetizzava nella seguente formula: «Tutto ciò che, del processo scritto, può essere oralizzato [...] lo sia, ma senza abdicare al diritto della conferma, dello schiarimento, del complemento o della contestazione e smentita mediante ciò che è stato scritto, e della esplicita lettura di ciò, che non può essere oralizzato». La flessibilità avrebbe evitato che, in nome d'un «principio giusto e liberale», si rinunciasse al «pieno raggiungimento della regina delle prove in criminale: l'intimo convincimento» ${ }^{73}$.

\section{RESISTENZE DELLA GIURISPRUDENZA}

Un circoscritto campione di giurisprudenza di fine Ottocento attesta che la spaccatura tra le scuole si propagava alle corti superiori, per le quali - è il caso di anticiparlo - l'immediatezza non incarnava affatto un dogma.

Nel 1884 Filippo Manduca, sostituto procuratore generale a Cagliari, annotava criticamente un'ordinanza del locale circolo d'assise straordinario che, in un processo per grassazione, aveva acconsentito alla lettura di lettere anonime in dibattimento. Invano Manduca, che in quella causa aveva svolto le funzioni di pubblico ministero, si era opposto al provvedimento, ritenendolo una violazione all'art. 311 c.p.p.

73 BERENINI, Agostino. Limiti della prova in criminale. Brevi considerazioni con particolare riferimento all'articolo 848 del codice di procedura penale. Parma: Luigi Battei, 1887, p. 40-42. Nel saluto a Ferri (ivi, p. 5 n.n.) l'Autore si riprometteva di mostrare il riformismo gradualista della «scuola criminale antropologica, ma punto antropofaga». 
Nel commentarlo su «Il Filangieri», egli ricopiava quasi alla lettera gli encomi di Borsani e Casorati all'oralità. E riteneva inaccettabile che vi derogassero le lettere anonime, sintomi di «animo vigliacco», come insegnava la massima di Nicolini riportata in epigrafe: «Le nostre leggi non han permesso mai che alcuno attacchi un individuo senza mostrarsi». «Nel sistema dell'intimo convincimento», insisteva Manduca, pesavano «un gesto, un movimento, una parola» del testimone; il «moto degli occhi», l'«azione della pupilla» e delle narici, il «colorito delle guance», l'«incresparsi delle labbra», l'«affrettarsi del respiro», il «gesto delle mani, tutti i cambiamenti insomma [...] rivelatori delle emozioni» e percepiti dall'«occhio vivace del giurato» sul «volto del testimone» riverberavano sul giudice popolare una «luce vivissima». Al contrario, ammettere in giudizio missive non firmate avrebbe moltiplicato gli «errori giudiziari», ridotto la giustizia a «mancipio di un morale assassinio», disorientato i giurati poco «educati al giuridico apprezzamento» delle prove. «Luce, sempre luce. Non è rettorica - ma positivismo ${ }^{74}$.

Si noti che nel 1905, piú di vent'anni dopo, la seconda sezione penale della Cassazione annullò una condanna per truffa inflitta al conte Emilio d'Ayala dalla corte d'appello di Genova. I giudici supremi contestarono ai colleghi di merito d'aver attinto il proprio convincimento da una «fonte impura», ossia una misteriosa lettera spedita dall'Argentina. Non rilevava che la missiva fosse stata discussa in dibattimento con l'accordo della parte civile e dell'imputato: «Il principio dell'oralità dei giudizi penali [era] d'ordine pubblico» e non derogabile dal consenso delle parti (di cui all'art. 311) allorché il testimone non fosse stato neppure citato; bisognava vigilare affinché testimonianze stragiudiziali non eludessero una «conquista di civile progresso» ${ }^{75}$.

74 MANDUCA, Filippo. Gli anonimi ed il giudizio penale. Pensieri. Il Filangieri, vol. 9, pt. I, 1884, p. 552-556 e 558-562 (ud. 28 luglio 1884, causa Callai Felice e aa., pres. Siotto-Pintor). L'Autore citava ampiamente BORSANI, Giuseppe; CASORATI, Luigi. Codice di procedura penale italiano commentato [...]. Libro secondo [...]. Volume quarto. Milano: Giacomo Pirola, 1879, § 1351, p. 96-97 (v. supra, § 6, nt. 55); e NICOLINI, Niccola. Della procedura penale nel Regno delle Due Sicilie [...]. Parte seconda, vol. II. Napoli: Dalla Stamperia di M. Criscuolo, 1829, § 379, p. 115-116.

75 Cass. pen., II sez., 22 dicembre 1905, ric. D’Ayala Emilio, pres. Petrella, rel. Ricco, p.m. De Francesco. Rivista Penale, vol. 63, 1906, p. 287-290. Il conte 
Negli anni Novanta la Cassazione mostrava vistosi ondeggiamenti. Nel 1890, ad esempio, la Suprema Corte ritenne violata l'oralità dal giudice di merito che aveva tratto «argomento della reità» da dichiarazioni rese in altro procedimento ${ }^{76}$. Due anni dopo, invece, essa giudicò «corretto» il verbale nel quale si dava atto che, durante l'interrogatorio dibattimentale, l'imputato aveva risposto conformemente a quanto dichiarato negli interrogatori scritti precedenti. Una breve nota anonima su «Cassazione Unica», nel registrare il revirement, eccepiva: o l'imputato si era semplicemente rimesso all'interrogatorio scritto, ma ciò gli era vietato «dacché egli deve oralmente rispondere sui fatti della causa»; oppure aveva «risposto, come doveva, oralmente», ma in tal caso non si vedeva chi - non certo un cancelliere - potesse verificare la supposta conformità con le pregresse dichiarazioni. «In ogni modo», constatava «con dolore» l'annotatore, «la vecchia giurisprudenza fu mutata» ${ }^{77}$.

Uno dei leading case concernenti la violazione dell'oralità (con evidenti implicazioni sull'immediatezza probatoria) fu originato da una truffa ai danni dell'Esattoria delle imposte. Nell'aprile del 1891 la Corte d'assise straordinaria di Roma puní con la reclusione Paride Fioravanti e taluni complici per appropriazione indebita e falsità in atto pubblico. I condannati (Fioravanti era assistito da un blasonato collegio difensivo) presentarono ricorso sostenendo che la Corte d'assise avesse violato il principio di oralità sotto vari aspetti. Anzitutto, essa aveva consentito, contro il dettato dell'art. 311, che il querelante (qualifica peraltro contestata) si limitasse a confermare i suoi «deposti scritti», mentre invece

d'Ayala era difeso da De Nicola, Raimondi e Ronchetti.

76 Cass. Pen., ud. 17 gennaio 1890, pres. e rel. De Cesare, p.m. Dei Bei, ric. Serafini. Cassazione Unica, v. 1, 1889, p. 204: la Corte di Cassazione annullò una sentenza della corte d'appello di Lucca, la quale aveva condannato per oltraggio Serafino Serafini desumendone la colpevolezza dall'istruttoria di altro processo contro un falso testimone. Analogamente, cfr. Cass. Pen., Ud. 29 ottobre 1891, pres. De Cesare, est. Parenti, p.m. Felici, ric. Antonio Romano. Cassazione Unica, IV (1893), vol. III, coll. 132-133: «Viola la oralità nei giudizi penali la sentenza che si fonda sulle dichiarazioni di testimoni non chiamati né esaminati nel pubblico giudizio».

77 Cass. Pen., Ud. 23 febbraio 1892, pres. Nobile, rel. Petrella, p.m. Sacchini, ric. Zappalà e aa., avv. De Benedetti ed Escobedo. Cassazione Unica, IV (1893), vol. III, col. 614 e ivi, nt. 2. 
«il pubblico dibattimento non deve essere una semplice e nuda ratifica della istruzione preparatoria». In secondo luogo, la Corte d'assise non solo aveva esaminato un testimone infermo «in una forma illegale», e cioè «facendogli leggere e confermare le dichiarazioni scritte», ma addirittura, accòrtasi dell'errore, aveva disposto ex novo un secondo esame: il quale però - eccepivano i difensori - era stato reso dall'ammalato sotto la plateale «influenza» della prima deposizione risalente a «poche ore prima» ${ }^{78}$.

La Corte di Cassazione respinse, rispetto a queste censure, il ricorso. Essa sostenne che l'oralità doveva considerarsi violata quando in dibattimento si fosse scelto di attingere alle deposizioni scritte nonostante la possibilità di ascoltare la viva voce del teste . Nel caso di specie, invece, tale opportunità non si era data: l'infermità del testimone aveva costretto, in udienza, a leggere il verbale della sua deposizione. E d'altro canto all'ammalato, ispettore dell'esattoria, dunque esperto «di numeri» e di «contabilità», si poteva senz'altro applicare l'art. 304 che concedeva a taluni testimoni, avuto riguardo alla loro qualità e alla natura della causa, di ricorrere a note e memorie. In base alle suddette considerazioni, la Cassazione annullò la sentenza di merito per la sola parte concernente l'entità della pena ${ }^{79}$.

È significativo il plauso riservato a questa pronuncia dal primo numero de «La Scuola positiva», che ne estrapolava, invero con qualche licenza, due massime di segno 'riduzionista'.

La prima: il divieto di lettura dibattimentale valeva solo per le deposizioni scritte dei testimoni, non per le dichiarazioni dei querelanti, per le quali si sarebbe addirittura profilato un ordine di leggerle dai verbali. L'anonimo annotatore della rivista spiegava: «Il principio della oralità del dibattimento non va inteso in un modo assoluto né portato agli estremi. Noi crediamo che esso sia già troppo esagerato e quindi non possiamo che plaudire ad ogni pronunziato della giurisprudenza che ne dia una interpretazione restrittiva, quando non si menomano le garanzie di difesa [...]. Ciò che è essenziale, ed è ad un tempo la vera conquista irrevocabile

78 VILLA, Tommaso; LOPEZ, Filippo; DE BENEDETTI, G. C.; GRIPPO, Pasquale. Corte di Cassazione penale - Per Paride Fioravanti - Motivi del ricorso - Udienza del 22 giugno 1891. Roma: Tipografia Cooperativa Operaia, 1891, p. 18-19.

79 Cass. Roma, ud. 22 giugno 1891, pres. Ghiglieri, est. Cocchia, ric. Fioravanti ed aa. Foro Italiano, v. 16, n. 2, 1891, col. 306-311. 
della oralità, è la garanzia cosí del giudicabile come della società giudicante, consiste nel fare in modo che chi deve giudicare possa apprezzare de visu (fuori dai preconcetti o dalla malizia possibile dell'autorità inquirente) l'indole, la capacità, il grado di convinzione dei testimoni; tutte cose che, quando non sono accompagnate da esatte nozioni di psicologia, a poco o nulla giovano» ${ }^{80}$.

La seconda massima che la redazione de «La Scuola positiva» astraeva dalla sentenza Fioravanti riguardava la possibilità di leggere al testimone, in dibattimento, la sua deposizione scritta prima di raccogliere quella orale. «Però - puntualizzava il redattore - non in senso assoluto»: era vero che alle forze dell'ordine, prima di sentirle in udienza, si permetteva di rileggere le dichiarazioni messe a verbale, ma occorreva evitare che il testimone comune approfittasse della pre-lettura per coprire eventuali «menzogne». Comunque, concludeva l'anonimo commento, «anche qui siamo di fronte alla solita necessità di riformare i nostri sistemi processuali secondo i dati positivi della psicologia e sociologia» ${ }^{81}$.

\section{La stagione di Finocchiaro-Aprile}

La lunga gestazione del codice Finocchiaro-Aprile, avviata dallo stesso guardasigilli palermitano nel 1898 e culminata nella promulgazione del 1913, forní l'occasione per un confronto ad ampio spettro sia sulla perdurante valenza del principio di oralità / immediatezza sia sulle soluzioni tecniche piú idonee a salvaguardarlo.

Nei primi giorni di gennaio del 1899 la commissione istituita dal ministro discuteva dell'assetto del futuro dibattimento. Pietro Nocito, ordinario all’Università di Roma, penalista ‘classico' e parlamentare di lungo corso, stigmatizzò «la consuetudine di costringere i testimoni a deporre sulla falsariga della istruzione scritta»: il «giudizio orale», raccomandava il professore siciliano, non doveva diventare «una seconda edizione del processo scritto». Due giorni dopo, all'unanimità,

80 Massimario critico della giurisprudenza penale. La Scuola Positiva, v. 1, 1891, n. 29, p. 308.

81 Massimario critico della giurisprudenza penale. La Scuola Positiva, v. 1, 1891, n. 30 , p. 309. 
la commissione approvava la mozione Nocito: «Limitare, per quanto è possibile, i casi nei quali si possa ricorrere alla lettura delle deposizioni scritte dei testimoni» ${ }^{82}$.

La sottocommissione incaricata, tra il 1902 e il 1904, di stilare un primo progetto si uniformò alla linea Nocito, nonostante l'opposto parere manifestato dalle magistrature: i sottocommissari spiegarono che «la verità nei giudizi penali non può essere messa in luce dagli atti scritti» perché «il giudice deve vedere il contegno, i gesti, gli scatti, i mutamenti e i turbamenti dei testimoni». Ma la commissione di revisione ribaltò questo indirizzo e tornò ad ammettere la derogabilità al divieto di lettura previo accordo delle parti, con ciò dimostrando di non credere al valore assoluto, o di ordine pubblico, del principio di oralità ${ }^{83}$.

Il primo articolato del futuro codice di rito, predisposto nel $1905 \mathrm{e}$ corredato d'una pregevole relazione di Finocchiaro-Aprile, vietava, in nome dell'oralità, la lettura delle deposizioni scritte (anche di quelle indirette, delle lettere dei congiunti etc.): le immancabili eccezioni (difformità rispetto a precedenti dichiarazioni, consenso delle parti) non consentivano, in ogni caso, la lettura integrale ${ }^{84}$. In un passaggio della Relazione dedicato

82 Lavori preparatorii del Codice di Procedura Penale per il Regno d'Italia. Atti della Commissione istituita con decreto 3 ottobre 1898 dal Ministro di Grazia e Giustizia e dei Culti (Finocchiaro-Aprile) con l'incarico di studiare e proporre le modificazioni da introdurre nel vigente Codice di procedura penale. Volume primo. Roma: Tipografia della Camera dei Deputati, 1900, vb. V (5 gennaio 1899), p. 42; ivi, vb. VII (7 gennaio 1899), p. 70. Nello stesso spirito la commissione proponeva di ridurre all'essenziale la lettura, in apertura di dibattimento, della sentenza di rinvio a giudizio (o dell'atto di citazione) e di abolire il riassunto presidenziale: ivi, Volume secondo. Roma: Tipografia della Camera dei Deputati, 1900, vb. XL (4 marzo 1900), p. 100-102.

FERRUA, Paolo. Oralità del giudizio e letture di deposizioni testimoniali. Milano: Giuffrè, 1981, p. 168-169 (da cui è tratta anche la cit. della sottocommissione), p. $177,185$.

FINOCCHIARO-APRILE, Camillo. Relazione sul progetto del nuovo codice di procedura penale presentata [...] alla Camera dei Deputati nella seduta del 28 novembre 1905. Legislatura XXII - Sessione 1904-1905. Camera dei Deputati - Stampato num. 266. In: MORTARA, Lodovico; STOPPATO, Alessandro; VACCA, Guglielmo; SETTI, Augusto; DE NOTARISTEFANI, Raffaele; LONGHI, Silvio (a cura di). Commento al Codice di procedura penale. Parte Prima - Lavori preparatorii. Volume secondo: I progetti ministeriali del 1905 e del 1911 (Relazioni e Testi). Torino: Unione Tipografico-Editrice Torinese, 1913, $\S$ CXXIV, p. 320-321. 
al superamento dell'istruzione segreta il guardasigilli osservava che, mentre il giudice togato, diffidente «d'abitudine dei risultamenti del pubblico dibattimento», s'ingegnava a ridurlo a «copia esatta e fedele dell'istruzione scritta», i giurati sospettavano proprio di quest'ultima: a loro bastava «il piú lieve mutamento nella deposizione di un testimone» o la scoperta d'un errore nel processo scritto per metterne in discussione anche i «risultamenti» apparentemente indubbi. Il diverso atteggiamento, chiosava il ministro senza drammatizzare, era «nella natura delle cose»: da un lato la fiducia dei 'professionisti' nella «prova raccolta nell'ombra», dall'altro lo scetticismo della «coscienza popolare» verso il segreto istruttorio ${ }^{85}$.

Nella Relazione di accompagnamento al successivo progetto di codice (1911) il tema dell'oralità trovava piú ampio sviluppo. Occorre premettere che in questo secondo articolato la citazione diretta (istituto che rimpiazzava l'istruzione sommaria del c.p.p. 1865) diveniva regola per i giudizi 'minori' (ossia non riservati alla corte d'assise) ed era congegnata in modo che le indagini del pubblico ministero non avessero altro fine che di «preparare l'accusa, e mai» quello di ipotecare il giudizio o la sentenza. «Nell'animo del giudice» - precisava Finocchiaro-Aprile con un fraseggio stentoreo che gli sarebbe stato, piú tardi, rimproverato - la prova avrebbe dovuto «prospettarsi unicamente quale sorge dal dibattimento, sotto l'egida della pubblicità e il controllo delle parti»: grazie all'«attitudine» dei togati a formarsi il convincimento «sull'attrito delle contestazioni», l'istruzione doveva «essere orale»; «il resto, di regola, non d[oveva] esistere per il giudice ${ }^{86}$.

85 FINOCCHIARO-APRILE, Camillo. Relazione sul progetto del nuovo codice di procedura penale presentata [...] alla Camera dei Deputati nella seduta del 28 novembre 1905. Legislatura XXII - Sessione 1904-1905. Camera dei Deputati - Stampato num. 266. In: MORTARA, Lodovico; STOPPATO, Alessandro; VACCA, Guglielmo; SETTI, Augusto; DE NOTARISTEFANI, Raffaele; LONGHI, Silvio (a cura di). Commento al Codice di procedura penale. Parte Prima - Lavori preparatorii. Volume secondo: I progetti ministeriali del 1905 e del 1911 (Relazioni e Testi). Torino: Unione Tipografico-Editrice Torinese, 1913, § LXIV, p. 155-156. Cfr. FERRUA, Paolo. Oralità del giudizio e letture di deposizioni testimoniali. Milano: Giuffrè, 1981, p. 115.

86 FINOCCHIARO-APRILE, Camillo. Relazione sul progetto del nuovo codice di procedura penale presentata dal ministro di Grazia e Giustizia [...] al Senato del Regno nella seduta del 23 maggio 1911. Legislatura XXIII - Sessione I. Senato del Regno - Stampato n. 544. In: MORTARA, Lodovico; STOPPATO, 
Per conseguire questo obiettivo il ministro non vedeva che una strada: vietare la lettura, in dibattimento, di «qualsiasi atto raccolto senza l'intervento del giudice». Egli era consapevole che una cosí drastica misura collideva con «le annose nostre consuetudini giudiziarie», per le quali l'istruzione scritta (formale, preliminare del p.m., e ancor piú spesso delegata al pretore) «traccia[va] la via al convincimento del giudice». Anzi, deplorava la Relazione citando Mittermaier, spesso sia il presidente del dibattimento sia il pubblico ministero si adoperavano per trarre dalla «pubblica discussione la conferma dei risultati del processo scritto» ${ }^{87}$.

Finocchiaro-Aprile si riferiva al breve scritto del 1866 Il giudizio popolare nella forma del giurí, che l'ex ministro Giuseppe Vacca aveva fatto tradurre due anni dopo da Carlo Dura. In quel saggio Mittermaier aveva sostenuto che solo la giuria assicurava una piena oralità, ossia che il giudice si pronunciasse sulla base delle risultanze della «pubblica discussione, senza aver letto gli atti provenienti da un giudizio preconcetto sul caso». Per contro, dai togati - secondo il giurista bavarese - vi era sempre da temere che, attraverso la conoscenza degli atti istruttori, andassero «involontariamente» in sessione «con una opinione preconcetta» circa la «reità» dell'imputato; e che, nel contrasto tra la deposizione ascoltata in udienza e quella inserita nel fascicolo, inclinassero per quest'ultima ${ }^{88}$.

Alessandro; VACCA, Guglielmo; SETTI, Augusto; DE NOTARISTEFANI, Raffaele; LONGHI, Silvio (a cura di). Commento al Codice di procedura penale. Parte Prima - Lavori preparatorii. Volume secondo: I progetti ministeriali del 1905 e del 1911 (Relazioni e Testi). Torino: Unione Tipografico-Editrice Torinese, 1913, § XVII, p. 619 (cfr. infra, § 11). Criticava questo passaggio del progetto 1911 PETROCELLI, Biagio. Azione - istruzione - accusa. Rivista Penale, fsc. 1-2, 1931, p. 237 ss., ora in PETROCELLI, Biagio. Saggi di diritto penale. Padova: Cedam, 1952, p. 601.

FINOCCHIARO-APRILE, Camillo. Relazione sul progetto del nuovo codice di procedura penale presentata dal ministro di Grazia e Giustizia [...] al Senato del Regno nella seduta del 23 maggio 1911. Legislatura XXIII - Sessione I. Senato del Regno - Stampato N. 544. In: MORTARA, Lodovico; STOPPATO, Alessandro; VACCA, Guglielmo; SETTI, Augusto; DE NOTARISTEFANI, Raffaele; LONGHI, Silvio (a cura di). Commento al Codice di procedura penale. Parte Prima - Lavori preparatorii. Volume secondo: I progetti ministeriali del 1905 e del 1911 (Relazioni e Testi). Torino: Unione Tipografico-Editrice Torinese, 1913, § XVIII, p. 622-623. und Schöffengerichte, Berlin 1866, tr. it. Il giudizio popolare nella forma del giurí 
Confortata da questo autorevole caveat, la Relazione al progetto 1911 constatava che il dibattimento italiano era «ridotto dagli attuali nostri costumi giudiziari a niente altro che ad una lettura e ad una ratifica del processo scritto» e che le sentenze si reggevano, per lo piú, su elementi di prova pre-dibattimentali. Poiché - notava il ministro - «noi siamo formalisti per natura e per abitudine», l'oralità era degradata a «formale sfilata di testimoni» che si limitavano a «confermare, spesso senza neppure ripetere, qualche volta senza neppure comprendere, la deposizione già fatta»; per salvare nominalmente il principio ci si accontentava di controllare che nella sentenza non fosse rifluita, per una svista, qualche affermazione proveniente da teste non comparso al dibattimento ${ }^{89}$.

La soluzione escogitata dal progetto 1911, che recuperava lo spirito della già citata ( $§ 5$ ) circolare Villa (25 gennaio 1880) sull'istruzione sommaria, consisteva nel distinguere tra atti di ricerca, «attribuiti al pubblico ministero», e «atti di conservazione e accertamento delle prove, deferiti al giudice in contraddizione delle parti». «Vada pure l'accusatore - scandiva il guardasigilli - con la sua accusa preparata e ordinata all'udienza, ma non il giudice, il quale deve ricevere la sua prima e unica impressione dalla discussione orale delle prove, e su questa soltanto deve fondare la sentenza» ${ }^{90}$. L'art. 469 , con formula

e del Tribunale degli scabini secondo le moderne legislazioni. Recato in italiano dall'Avvocato Carlo Dura e pubblicato per la cura di Giuseppe Vacca [...]. Napoli: Stabilimento Tipografico di Salvatore Marchese, 1868, p. 35-37.

FINOCCHIARO-APRILE, Camillo. Relazione sul progetto del nuovo codice di procedura penale presentata dal ministro di Grazia e Giustizia [...] al Senato del Regno nella seduta del 23 maggio 1911. Legislatura XXIII - Sessione I. Senato del Regno - Stampato N. 544. In: MORTARA, Lodovico; STOPPATO, Alessandro; VACCA, Guglielmo; SETTI, Augusto; DE NOTARISTEFANI, Raffaele; LONGHI, Silvio (a cura di). Commento al Codice di procedura penale. Parte Prima - Lavori preparatorii. Volume secondo: I progetti ministeriali del 1905 e del 1911 (Relazioni e Testi). Torino: Unione Tipografico-Editrice Torinese, 1913, \& XVIII, p. 623-624.

90 FINOCCHIARO-APRILE, Camillo. Relazione sul progetto del nuovo codice di procedura penale presentata dal ministro di Grazia e Giustizia [...] al Senato del Regno nella seduta del 23 maggio 1911. Legislatura XXIII - Sessione I. Senato del Regno - Stampato N. 544. In: MORTARA, Lodovico; STOPPATO, Alessandro; VACCA, Guglielmo; SETTI, Augusto; DE NOTARISTEFANI, Raffaele; LONGHI, Silvio (a cura di). Commento al Codice di procedura penale. Parte Prima - Lavori preparatorii. Volume secondo: I progetti ministeriali 
particolarmente lineare e avanzata ${ }^{91}$, vietava, salvo eccezioni tassative, la lettura di qualsiasi scritto. Come si vedrà, questa scelta sarebbe stata rinnegata dal codice entrato in vigore due anni dopo.

Il progetto 1911 fu sottoposto al vaglio di due commissioni parlamentari. Quella della Camera, in particolare, relatore Alessandro Stoppato, frenava gli slanci in materia di oralità: «Qui non bisogna eccedere. Si deve vietare senza distinzione la lettura di scritti? Crediamo di no», specie ove la deroga avesse riguardato documenti non contestati dalle parti; «dato il sistema del libero convincimento», bastava delimitare il principio in questione «in ragionevoli confini» e «in rapporto agli scopi del moderno diritto processuale» ${ }^{92}$.

Il testo definitivo del c.p.p. 1913 canalizzò in tre gruppi la macchinosa disciplina della lettura delle testimonianze ${ }^{93}$. Rispetto alle

del 1905 e del 1911 (Relazioni e Testi). Torino: Unione Tipografico-Editrice Torinese, 1913, § XVIII, p. 624-625.

91 FERRUA, Paolo. Oralità del giudizio e letture di deposizioni testimoniali. Milano: Giuffrè, 1981, p. 200.

92 STOPPATO, Alessandro. Relazione della Commissione nominata dal presidente della Camera composta dei deputati Grippo presidente, Dari segretario, Barzilai, Daneo, Ferri Enrico, Fulci, Girardi, Muratori e Stoppato relatore sul progetto del codice di procedura penale per il Regno d'Italia e sul disegno di legge che ne autorizza la pubblicazione approvato dal Senato del Regno il 7 marzo 1912 (v. stampato n. 544) presentato dal ministro di grazia e giustizia e dei culti nella tornata dell'8 marzo 1912. In: MORTARA, Lodovico; STOPPATO, Alessandro; VACCA, Guglielmo; SETTI, Augusto; DE NOTARISTEFANI, Raffaele; LONGHI, Silvio (a cura di). Commento al Codice di procedura penale. Parte Prima - Lavori preparatorii. Volume terzo. Lavori parlamentari (relazioni, discussioni) e redazione definitiva del Codice e delle norme di attuazione e transitorie. Torino: Unione Tipografico-Editrice Torinese, 1914, p. 301-302.

I tre gruppi erano cosí suddivisi. 1) Letture sempre ammesse: deposizioni raccolte nel corso di ispezioni, esperimenti etc. $\left(404^{2}\right)$; testimonianze a futura memoria o rese da soggetti o in situazioni peculiari. 2) Letture ammesse al verificarsi di specifiche condizioni: testimonianze esaminate da un giudice con le norme dell'istruzione formale, e sulle quali vi fosse consenso delle parti (art. 406 = art. 311 c.p.p. 1865); testimonianze indicate nelle rispettive liste dalle parti; deposizioni di testi morti o assenti; dichiarazioni difformi rispetto a quelle istruttorie, con possibilità di «consultare note in aiuto della memoria» (art. 3973); dichiarazioni istruttorie necessarie a «far risultare contraddizioni o variazioni nelle deposizioni al dibattimento» (art. 4042 ${ }^{2}$. 3) Letture vietate a pena di nullità (art. 406): deposizioni non esaminate dal giudice «con le norme dell'istruzione formale»; deposizioni di congiunti o 
premesse balenate nei due progetti, la restaurazione era palese: la barriera dell'oralità si rivelava, ancora una volta, ampiamente e forse persino piú perforabile, come rilevava il piú irriducibile oppositore di quel codice ${ }^{94}$ e come conferma una fine disamina storiografica ${ }^{95}$.

Di segno opposto, e decisamente benevolo, era invece il bilancio tracciato da Raffaele De Notaristefani, magistrato napoletano che aveva avuto un ruolo non marginale nel corso dei lavori preparatori. Nel suo commentario lo studioso sgomberava súbito il campo dai retro-pensieri: la griglia prevista dal nuovo c.p.p. a proposito di leggibilità degli atti scritti sottintendeva una piena accettazione del principio di oralità, coi suoi «vantaggi diretti», vale a dire la «simultaneità della percezione» e la capacità della «parola» di suscitare attenzione; e con $\mathrm{i}$ «vantaggi indiretti», cioè pubblicità, contraddittorio, immediatezza ${ }^{96}$.

Come già s'intuisce da questa excusatio, De Notaristefani divaricava la sfera dell'oralità da quella dell'immediatezza. A suo parere, la nuova disciplina codicistica presentava «una doppia efficacia: implicitamente afferma[va] il

interrogatori di prosciolti; «informazioni sulle voci correnti nel pubblico». Cfr. FERRUA, Paolo. Oralità del giudizio e letture di deposizioni testimoniali. Milano: Giuffrè, 1981, p. 203-206, 206-210, 212-219. Ivi, pp. 221-225 quanto alla lettura dei verbali di polizia giudiziaria. Sulla norma di chiusura (art. 407, anch'esso generoso soprattutto se applicato ai rapporti di polizia), che autorizzava il presidente a dar lettura di qualsiasi documento laddove ne ravvisasse la «pertinenza» e l'«utilità», ivi, pp. 225-229; ivi, p. 134-136 per le corrispondenti regole del c.p.p. 1865.

LUCCHINI, Luigi. Elementi di procedura penale. Quarta edizione interamente riveduta e ampliata. Firenze: Barbèra, 1920, n. 285, p. 360-361 denunciava che il c.p.p. 1913, invertendo la logica di quello previgente, poneva come regola la leggibilità delle deposizioni a condizione che le parti vi consentissero. I numerosi casi di letture ammesse inducevano il penalista veneto a ritenere «un po' troppo facilmente compromesse» dalle influenze istruttorie «l'oralità e l'autonomia del dibattimento».

FERRUA, Paolo. Oralità del giudizio e letture di deposizioni testimoniali. Milano: Giuffrè, 1981, p. 200.

DE NOTARISTEFANI, Raffaele. Del giudizio. In: MORTARA, Lodovico; STOPPATO, Alessandro; VACCA, Guglielmo; SETTI, Augusto; DE NOTARISTEFANI, Raffaele; LONGHI, Silvio (a cura di). Commento al Codice di procedura penale. VI - Codice di procedura penale. Libro Terzo. Torino: Unione Tipografico-Editrice, 1915, p. 585-586. Sul ruolo del De Notaristefani nell'elaborazione del c.p.p. 1913 v. MILETTI, Marco Nicola. Un processo per la Terza Italia. Il codice di procedura penale del 1913. I: L’attesa. Milano: Giuffrè, 2003, ad indicem. 
principio di oralità, esplicitamente regola[va] nel dibattimento il principio di immediatezza delle prove». L'oralità «in senso proprio» riguardava il «momento di comunicazione e di discussione delle prove»: orale era il processo in cui le proposte delle parti erano presentate «oralmente», «gli oggetti di ispezione [era]no sottoposti alla visione del giudice nel dibattimento, le altre prove si forma[va]no oralmente o [era]no lette, la discussione di tutte le proposte e di tutte le prove [era] orale e il giudice fonda[va] la propria convinzione esclusivamente sopra elementi di fatto risultanti al dibattimento ${ }^{97}$.

L'apparato di citazioni con il quale De Notaristefani suffragava queste prime considerazioni denota un sapiente scrutinio della letteratura, anche straniera. Da Julius Glaser egli traeva la distinzione concettuale tra immediatezza, riguardante la formazione delle prove, e oralità, attinente alla discussione delle medesime. Dal manuale di Adolf von Kries attingeva l'ancor piú drastica affermazione secondo cui l'oralità (Mündlichkeit) non aveva nulla a che vedere con l'assunzione della prova (Methode der Beweisaufnahme $)^{98}$. Dal recentissimo Trattato del Manzini, infine, De Notaristefani mutuava l'idea per cui la lettura dibattimentale, se da un lato oralizzava gli atti scritti rendendoli «conformi allo spirito del dibattimento», non soddisfaceva però il principio, altrettanto «fondamentale», dell'immediatezza: e perciò andava «limitata tassativamente ai casi preveduti dalla legge, escludendo ogni efficacia derogatoria alla volontà del giudice o al consenso degli altri soggetti processuali» ${ }^{99}$.

97 DE NOTARISTEFANI, Raffaele. Del giudizio. In: MORTARA, Lodovico; STOPPATO, Alessandro; VACCA, Guglielmo; SETTI, Augusto; DE NOTARISTEFANI, Raffaele; LONGHI, Silvio (a cura di). Commento al Codice di procedura penale. VI - Codice di procedura penale. Libro Terzo. Torino: Unione Tipografico-Editrice, 1915, p. 584 e ivi, nt. 1.

98 Rispettiv. GLASER, Julius. Handbuch des Strafprozesses. Erster Band. In BINDING, Karl (hrsg.), Systematisches Handbuch der Deutschen Recthtswissenschaft [...]. Neunte Abtheilung, vierter Theil, erster Band. Leipzig: Verlag von Duncker \& Humblot, 1883, p. 247; VON KRIES, August. Lehrbuch des Deutschen Strafprozessrechts. Freiburg: Akademische Verlagsbuchhandlung von J.C.B. Mohr, 1892, p. 251.

99 MANZINI, Vincenzo. Trattato di procedura penale italiana secondo il nuovo c.p.p. e le nuove leggi di ord. giud. - Volume II. Torino: Fratelli Bocca, 1914, n. 425 , p. 452. Identica espressione si ritrova in MANZINI, Vincenzo. Trattato di diritto processuale penale italiano secondo il nuovo codice. Con prefazione di Alfredo Rocco Ministro della Giustizia. Volume quarto. Torino: Unione Tipografico-Editrice Torinese, 1932, n. 425, p. 346. 
Le fonti assemblate conducevano De Notaristefani a enunciare perentorio: «Nel significato proprio l'oralità si distingue dalla immediatezza». In nota egli contrapponeva i fautori dell'identificazione (Planck, Zachariae, Fuchs, Richard Ed. John, Geyer, Borsani-Casorati) alle opere che avevano teorizzato la distinzione (primo tra tutti, un saggio di von Kries del 1886, cui aveva fatto séguito il Lehrbuch di Ernst Beling e Hans Bennecke, per arrivare infine agli scritti di Chiovenda) ${ }^{100}$.

Dell'immediatezza De Notaristefani forniva una definizione criptica («mancanza di interposizione di un mezzo di prova fra un altro mezzo di prova e il giudice»), incentrata sul rebus della prova mediata; e una descrizione stereotipata (la fedeltà della parola, del «tono di voce», del contegno, a fronte della «menomazione» della scrittura). A suo avviso, isolarne il concetto consentiva, sul piano ermeneutico, di costruire un'autonoma disciplina della leggibilità degli atti a prescindere dal 'formato', scritto o orale, in cui questi si presentassero ${ }^{101}$.

\section{Cenno agli SVilupPI NOVECEnTESCHI}

Forse in polemica con le riluttanze della propria disciplina, Chiovenda avrebbe attribuito al codice del 1913 (da lui collocato entro

${ }^{100}$ DE NOTARISTEFANI, Raffaele. Del giudizio. In: MORTARA, Lodovico; STOPPATO, Alessandro; VACCA, Guglielmo; SETTI, Augusto; DE NOTARISTEFANI, Raffaele; LONGHI, Silvio (a cura di). Commento al Codice di procedura penale. VI - Codice di procedura penale. Libro Terzo. Torino: Unione Tipografico-Editrice, 1915, p. 586 e ivi, nt. 2. L'Autore citava, in particolare, BORSANI, Giuseppe; CASORATI, Luigi. Codice di procedura penale italiano commentato [...]. Libro secondo [...]. Volume quarto. Milano: Giacomo Pirola, 1879, § 1351, p. 96 (v. supra, § 6, nt. 55); VON KRIES, August. Das Prinzip der Unmittelbarkeit im Beweisverfahren der Deutschen Prozessordnung. Zeitschrift für die gesamte Strafrechtswissenschaft, v. 6, n. 1-2, 1886, p. 88-203, spec. p. 102; JOHN, Richard Ed. Das Deutsche Strafprozessrecht. Mit Rücksicht auf die Justizgesetze des Deutschen Reichs in den Grundzügen systematisch dargestellt. Leipzig: Duncker \& Humblot, 1882, § 6.

${ }^{101}$ DE NOTARISTEFANI, Raffaele. Del giudizio. In: MORTARA, Lodovico; STOPPATO, Alessandro; VACCA, Guglielmo; SETTI, Augusto; DE NOTARISTEFANI, Raffaele; LONGHI, Silvio (a cura di). Commento al Codice di procedura penale. VI - Codice di procedura penale. Libro Terzo. Torino: Unione Tipografico-Editrice, 1915, p. 586-588. 
una piú generale, propizia congiuntura) il merito d'aver accresciuto «l'importanza del dibattimento» e portato «alle ultime conseguenze l'oralità in materia penale, rendendo insieme sempre piú stridente il contrasto col carattere del nostro processo civile» ${ }^{102}$.

La storiografia si sarebbe incaricata di raffreddare simili entusiasmi ${ }^{103}$. È tuttavia innegabile che un qualche apporto anche simbolico al tópos dell'immediatezza il codice giolittiano lo avesse realmente arrecato. Basti pensare che nel 1931 Biagio Petrocelli, anche al fine di enfatizzare il cambio di marcia impresso da Alfredo Rocco, si premurò di rivangare, per denunciarne l'impraticabilità, la promessa formulata dalla Relazione Finocchiaro-Aprile al progetto 1911 (peraltro non mantenuta dal testo definitivo del 1913): e cioè che le prove sarebbero dovute emergere esclusivamentedal dibattimentoe che qualsiasi elemento probatorio esorbitante da quest'ultimo avrebbe dovuto considerarsi inesistente. Affermazioni cosí ardite, protestava Petrocelli, si erano nutrite della sfiducia nella giustizia e della retorica dell'«imputato-vittima», ma erano «smentit[e] dalla realtà»: nessun giudice, «pur traendo anche dalle vive e dirette impressioni del dibattimento fondamento per le sue convinzioni», avrebbe potuto prescindere del tutto dall'istruzione, la cui

${ }^{102}$ CHIOVENDA, Giuseppe. Relazione sul progetto di riforma del procedimento elaborato dalla Commissione per il dopo guerra. Napoli: Jovene, 1920; poi in: CHIOVENDA, Giuseppe. Saggi di diritto processuale civile (1900-1930). Nuova edizione considerevolmente aumentata dei "Saggi" e dei "Nuovi saggi". Volume secondo. Roma: Società Editrice «Foro Italiano», 1931 [rist. anast. Milano: Giuffrè, 1993], p. 19-20. L'Autore si riferiva al r.d. 20 marzo 1913, n. 289 (Ordinamento giudiziario per la Tripolitania e la Cirenaica), la cui Relazione al Re aveva rivendicato l'adozione dei criteri del concentramento e dell'immediatezza del processo; e al r.d. 27 agosto 1913, n. 1015 (funzionamento del giudice unico). Già nel 1913 (ma quando il nuovo c.p.p. non era ancora entrato in vigore) CHIOVENDA, Giuseppe. Principii di diritto processuale civile [...]. $3^{\mathrm{a}}$ edizione riveduta e notevolmente aumentata. Napoli: Jovene, 1913, § 44, p. 680, nt. 2 aveva osservato che, mentre la dottrina studiava la riforma del codice processuale civile, il recente progetto Finocchiaro-Aprile (1911) di codice penale di rito aveva «rinvigorito il principio e le sanzioni dell'oralità».

${ }^{103}$ FERRUA, Paolo. Oralità del giudizio e letture di deposizioni testimoniali. Milano: Giuffrè, 1981, p. 198-201 (con particolare riguardo ai regressi registrati in materia di oralità e nel dibattimento); MILETTI, Marco Nicola. Un processo per la Terza Italia. Il codice di procedura penale del 1913. I: L’attesa. Milano: Giuffrè, 2003, p. 441. 
forza, a dispetto delle «teoriche affermazioni di principio», risiedeva nella «immediata prossimità e aderenza al fatto». La precipua attività del giudice del dibattimento - proseguiva il giurista napoletano - era «di controllo» 0 , eccezionalmente, «di integrazione della prova, non di creazione di essa. $\mathrm{E}$ ciò - si noti - non soltanto perché nel dibattimento manca quel piú vivo e diretto contatto col fatto che può esservi nella istruzione, ma anche perché officio vero del giudice è di giudicare sugli elementi presentati da altri soggetti del processo, non su quelli che si possa creare egli stesso» ${ }^{104}$.

L'inversione di priorità tra le fasi del processo ricacciava l'immediatezza nel limbo delle buone intenzioni, sebbene la dottrina, anche quella piú organica al regime, non la ripudiasse in linea di principio ${ }^{105}$. Bisognò attendere la battaglia progressista per il modello adversary e per un'effettiva cesura probatoria tra istruzione e dibattimento ${ }^{106}$ perché il concetto riacquistasse uno spessore garantista. «Le prove formate» in istruzione, ammoniva Franco Cordero nel 1963, andavano valutate ai fini della decisione sul rinvio a giudizio, ma «non trasmigra[va]no automaticamente nella fase successiva», dove se ne richiedeva il compimento ex novo ovvero la lettura mediante verbale. Tuttavia, rilevava con rammarico lo studioso piemontese, l'assetto del codice del 1930 retrocedeva alla fase istruttoria il centro gravitazionale del processo, «svaluta[va] il dibattimento» e disattendeva la coralità della formazione della prova. «Le suggestioni di una tenace tradizione inquisitoria» avevano «soverchiato [...] il principio d'oralità, nel significato caro a Chiovenda» ${ }^{107}$.

${ }^{104}$ PETROCELLI, Biagio. Azione - istruzione - accusa. Rivista Penale, 1931/II, p. 237 ss., ora in PETROCELLI, Biagio. Saggi di diritto penale. Padova: Cedam, 1952, p. 601-602 (csvv. dell'Autore).

105 MANZINI, Vincenzo. Trattato di diritto processuale penale italiano secondo il nuovo codice. Con prefazione di Alfredo Rocco Ministro della Giustizia. Volume quarto. Torino: Unione Tipografico-Editrice Torinese, 1932, n. 425, p. 346.

106 Per il contesto cfr. ORLANDI, Renzo. Diritti individuali e processo penale nell'Italia repubblicana. In NEGRI, Daniele; PIFFERI, Michele (a cura di). Diritti individuali e processo penale nell'Italia repubblicana. Milano: Giuffrè, 2011, p. 64-66.

${ }^{107}$ CORDERO, Franco. Scrittura e oralità nel rito probatorio. In: Studi in onore di Francesco Antolisei, I. Milano: Giuffrè, 1965, p. 311 ss.; e in CORDERO, Franco. Tre studi sulle prove penali. Milano: Giuffrè, 1963, p. 197, ntt. 41-42 (trasmigrazione); ivi, p. 203 (baricentro); ivi, p. 237 (tradizione inquisitoria). La lettura delle deposizioni, lamentava Cordero (ivi, p. 212-213), «spiega[va] 
Vàluti il lettore se, dopo oltre mezzo secolo e l'avvento d'un nuovo codice di rito, l'evoluzione della giustizia italiana incoraggi riflessioni meno cupe.

\section{Conclusioni}

Dalla traiettoria sin qui sinteticamente delineata emerge la sensibilità della processual-penalistica italiana per il canone dell'immediatezza. Se, durante la Restaurazione, gli studiosi ne reclamavano fieramente le matrici romanistiche, dopo l'Unità ne misero a profitto il risvolto costituzionale: un giudizio dipanantesi sotto gli occhi del giudice avrebbe, infatti, assicurato all'intera comunità la possibilità di verificare in ogni processo il corretto esercizio dei meccanismi probatori.

La realizzazione di questo ambizioso disegno passava attraverso un riequilibrio del processo misto o bifasico. Bisognava, cioè, restituire, o finalmente riconoscere, nel dibattimento pubblico e orale il momento deputato al vaglio ex novo delle prove istruttorie o, addirittura, all'acquisizione di ulteriori elementi. Un simile scenario, peraltro intralciato dagli angusti vincoli del codice di procedura penale del 1865, era osteggiato dalla scuola positiva, la quale confidava invece nei progressi della prova scientifica e nella crescente specializzazione dei magistrati e pretendeva perciò che i congegni del convincimento restassero saldamente riposti nel gabinetto dell'istruttore.

Nella pregevole riflessione sull'oralità, che per certi aspetti anticipava le notissime intuizioni chiovendiane, la processual-penalistica italiana riservò all'immediatezza, sin dall'ultimo scorcio del secolo XIX, una specifica attenzione. Non riuscí, tuttavia, a ritagliarne i precisi contorni e a costruire una teorica comparabile all'Unmittelbarkeit: lemma, quest'ultimo, che non a caso si rinunciò a tradurre. E cosí, nelle opere a piú larga diffusione, l'immediatezza continuò tralatiziamente a figurare nella griglia dei 'requisiti' del dibattimento, ma non assurse alla dignità di valore autonomo e indefettibile. Le sospette assonanze

la sottile suggestione delle cose scritte»: e rischiava di tramutare «il luogo comune del libero convincimento [...] in una salvaguardia del fatto compiuto». 
tra le definizioni disseminate nei trattati e nei manuali denotano, oltre che una certa pigrizia didascalica, l'inclinazione a proclamare princípi senza accertarne la coerenza sistematica né la concreta spendibilità nelle aule di giustizia.

\section{Biblografia}

AIUTI, Valerio. L'immediatezza presa sul serio. Diritto penale e processo, v. 1, 2019, p. 109-120.

AJELLO, Raffaele. I Sagi politici di Mario Pagano e il loro tempo. Il Pensiero politico, v. 28, n. 1, 1995, p. 17-57.

ALIMENA, Bernardino. Appunti di diritto e procedura penale, Cagliari: s.t., 1898-99.

BENTHAM, Jeremy. Traité des preuves judiciaires (1823), tr. it. Teoria delle prove giudiziarie [...]. Prima versione italiana del dottore Barnaba Vincenzo Zambelli. Brusselles: Tipografia della Società Belgica, 1842.

BERENINI, Agostino. Limiti della prova in criminale. Brevi considerazioni con particolare riferimento all'articolo 848 del codice di procedura penale. Parma: Luigi Battei, 1887.

BIROCCHI, Italo. In margine all'opera di Niccola Nicolini. Spunti per un manuale di storia giuridica dell'Ottocento. In: Tra diritto e storia. Studi in onore di Luigi Berlinguer promossi dalle Università di Siena e di Sassari. Soveria Mannelli: Rubbettino, 2008, I, p. 111-155.

BORSANI, Giuseppe; CASORATI, Luigi. Codice di procedura penale italiano commentato [...]. Libro secondo [...]. Volume quarto. Milano: Giacomo Pirola, 1879.

BRUSA, Emilio. Sul giurí, ad occasione delle recenti discussioni dei giuristi svizzeri [Torino, 20 gennaio 1882]. Rivista Penale, vol. 15, fsc. IV-V, 1882, p. 309-329.

CALAMANDREI, Piero. Oralità nel processo. In: Nuovo Digesto Italiano, IX. Torino: Utet, 1940, p. 178-180.

CALAMANDREI, Piero. Opere giuridiche, a cura di Cappelletti, Mauro. Volume primo. Napoli: Morano, 1965, pp. 450-455.

CAPPELLETTI, Mauro. Le grandi tendenze evolutive del processo civile nel diritto comparato. Giurisprudenza Italiana, v. 120, n. 4, 1968, coll. 1-48; ora in CAPPELLETTI, Mauro, Processo e ideologie. Bologna: il Mulino, 1969, p. 169-251. 
CAPPELLETTI, Mauro. L'oralità nel processo civile italiano: ideale contro realtà. Politica del diritto, III, n. 2 (aprile 1972), p. 189-201; nonché in CAPPELLETTI, Mauro. Giustizia e società. Milano: Edizioni di Comunità, 1972 [rist. 1977], p. 130-144.

CAPPELLETTI, Mauro. Il processo civile italiano nel quadro della contrapposizione «civil law»- «common law» (Appunti storico-comparativi). Rivista di diritto civile, v. 9, n. 1, 1963, p. 31-64; poi in CAPPELLETTI, Mauro. Processo e ideologie. Bologna: il Mulino, 1969, p. 287-338.

CAPPELLETTI, Mauro. Processo orale e processo scritto nel mondo contemporaneo (1970). In: CAPPELLETTI, Mauro. Giustizia e società. Milano: Edizioni di Comunità, 1972 [rist. 1977], p. 145-219.

CAPPELLETTI, Mauro. La testimonianza della parte nel sistema dell'oralità. Contributo alla teoria della utilizzazione probatoria del sapere delle parti nel processo civile. Parte prima [seconda]. Milano: Giuffrè, 1962.

CARNELUTTI, Francesco. La malattia del processo penale italiano. Rivista di diritto processuale, v. 17, 1962, p. 1-8.

CARRARA, Francesco. Il diritto penale e la procedura penale. Prolusione al corso di diritto criminale dell'a.a. 1873-74, nella R. Università di Pisa [Pisa, 12 novembre 1873]. In: CARRARA, Francesco. Programma del corso di diritto criminale. Del giudizio criminale. Con una selezione dagli Opuscoli di diritto criminale. Bologna: il Mulino, 2004, p. 415-441.

CHINNICI, Daniela. L'immediatezza nel processo penale. Milano: Giuffrè, 2005.

CHIOVENDA, Giuseppe. L'oralità e la prova. Rivista di diritto processuale civile, v. 1, n. 1, 1924, p. 5-32; poi col tit. Sul rapporto tra le forme del procedimento e la funzione della prova (L'oralità e la prova). In: CHIOVENDA, Giuseppe. Saggi di diritto processuale civile (1900-1930). Nuova edizione considerevolmente aumentata dei "Saggi” e dei "Nuovi saggi”. Volume secondo. Roma: Società Editrice «Foro Italiano», 1931 [rist. anast. Milano: Giuffrè, 1993], p. 197-225.

CHIOVENDA, Giuseppe. Principii di diritto processuale civile [...]. $3^{\text {a }}$ Edizione riveduta e notevolmente aumentata. Napoli: Jovene, 1913.

CHIOVENDA, Giuseppe. Principii di diritto processuale civile. Le azioni. Il processo di cognizione [1923]. Ristampa inalterata con prefazione del Prof. Virgilio Andrioli. Napoli: Jovene, 1980.

CHIOVENDA, Giuseppe. Relazione sul progetto di riforma del procedimento elaborato dalla Commissione per il dopo guerra. Napoli: Jovene, 1920; poi in CHIOVENDA, 
Giuseppe. Saggi di diritto processuale civile (1900-1930). Nuova edizione considerevolmente aumentata dei "Saggi" e dei "Nuovi saggi”. Volume secondo. Roma: Società Editrice «Foro Italiano», 1931 [rist. anast. Milano: Giuffrè, 1993], p. 1-196.

CHIOVENDA, Giuseppe. Le riforme processuali e le correnti del pensiero moderno [Conferenza al Circolo giuridico di Napoli, 11 marzo 1906], Rivista giuridica e sociale, 1907; poi in CHIOVENDA, Giuseppe. Saggi di diritto processuale civile (1900-1930). Nuova edizione considerevolmente aumentata dei "Saggi" e dei "Nuovi saggi”. Volume primo, Roma: Società Editrice «Foro Italiano», 1930 [rist. anast. Milano, Giuffrè 1993], p. 379-394.

CHIOVENDA, Giuseppe. Adolfo Wach. Rivista di diritto processuale civile, 1926; poi in CHIOVENDA, Giuseppe. Saggi di diritto processuale civile (1900-1930). Nuova edizione considerevolmente aumentata dei "Saggi" e dei "Nuovi saggi". Volume primo. Roma: Società Editrice «Foro Italiano», 1930 [rist. anast. Milano: Giuffrè, 1993], p. 263-268.

CLARO, Giulio. Liber Quintus Receptarum Sententiarum integer (1568). In: CLARO, Giulio. Opera omnia; sive Practica civilis, atque criminalis [...]. Venetiis: Apud Baretium Baretium, 1640.

CORDERO, Franco. Procedura penale. $8^{\mathrm{a}}$ ed. Milano: Giuffrè, 2006.

CORDERO, Franco. Scrittura e oralità nel rito probatorio. In: Studi in onore di Francesco Antolisei, I. Milano: Giuffrè, 1965, p. 311 ss.; e in: CORDERO, Franco. Tre studi sulle prove penali. Milano: Giuffrè, 1963, p. 173-240.

CORTESE, Paolo. Relazione sul codice di procedura penale. In: Codice di procedura penale del Regno d'Italia colla Relazione del ministro guardasigilli fatta a S.M. in udienza del 26 novembre 1865 [...]. Firenze: Stamperia Reale - Torino: Tip. Eredi Botta, 1866, p. III-XXXII.

DE NOTARISTEFANI, Raffaele. Del giudizio. In: MORTARA, Lodovico; STOPPATO, Alessandro; VACCA, Guglielmo; SETTI, Augusto; DE NOTARISTEFANI, Raffaele; LONGHI, Silvio (a cura di). Commento al Codice di procedura penale. VI - Codice di procedura penale. Libro Terzo. Torino: Unione Tipografico-Editrice, 1915.

DENTI, Vittorio. Chiovenda e le riforme del processo civile. Il Foro Italiano, v. 111 , n. 5, 1988, coll. 347-355.

DEZZA, Ettore. Il primo codice di procedura penale dell'Italia unita (1865). In: Codici penali. Padova-Torino: Cedam e Utet giuridica, 2011, p. LI-XCV.

FARINACCI, Prospero. Praxis et theoricae criminalis Partis Primae Tomus Secundus. Lugduni: Sumptibus Iacobi Cardon, 1634. 
FERRAJOLI, Luigi. Diritto e ragione. Teoria del garantismo penale. $9^{\mathrm{a}}$ ed. Roma-Bari: Laterza, 2008.

FERRERO, Guglielmo. I simboli in rapporto alla storia e filosofia del diritto alla psicologia e alla sociologia. Torino: Bocca, 1893.

FERRI, Enrico. Sociologia criminale. Terza edizione completamente rifatta dei Nuovi orizzonti del diritto e della procedura penale. Torino: Bocca, 1892.

FERRI, Enrico. Sociologia criminale. $4^{\mathrm{a}}$ ed. Torino: Bocca, 1900.

FERRUA, Paolo. Oralità del giudizio e letture di deposizioni testimoniali. Milano: Giuffrè, 1981.

FERRUA, Paolo. Teorie della prova: dialogo con Franco Cordero. Dis-Crimen, 16 dicembre 2020, p. 1-19.

FINOCCHIARO-APRILE, Camillo. Relazione sul progetto del nuovo codice di procedura penale presentata [...] alla Camera dei Deputati nella seduta del 28 novembre 1905. Legislatura XXII - Sessione 1904-1905. Camera dei Deputati Stampato num. 266. In: MORTARA, Lodovico; STOPPATO, Alessandro; VACCA, Guglielmo; SETTI, Augusto; DE NOTARISTEFANI, Raffaele; LONGHI, Silvio (a cura di). Commento al Codice di procedura penale. Parte Prima - Lavori preparatorii. Volume secondo: I progetti ministeriali del 1905 e del 1911 (Relazioni e Testi). Torino: Unione Tipografico-Editrice Torinese, 1913, p. 1-485.

FINOCCHIARO-APRILE, Camillo. Relazione sul progetto del nuovo codice di procedura penale presentata dal ministro di Grazia e Giustizia [...] al Senato del Regno nella seduta del 23 maggio 1911. Legislatura XXIII - Sessione I. Senato del Regno - Stampato n. 544. In: MORTARA, Lodovico; STOPPATO, Alessandro; VACCA, Guglielmo; SETTI, Augusto; DE NOTARISTEFANI, Raffaele; LONGHI, Silvio (a cura di). Commento al Codice di procedura penale. Parte Prima - Lavori preparatorii. Volume secondo: I progetti ministeriali del 1905 e del 1911 (Relazioni e Testi). Torino: Unione Tipografico-Editrice Torinese, 1913, p. 579-672.

FOSCHINI, Gaetano. Principio dell'immediatezza e principio della pubblicità. Nota a Cass., $2^{\text {a }}$ sez. pen., 21 gennaio 1953. Rivista italiana di diritto penale, 1953, p. 374; ora in FOSCHINI, Gaetano. Il dibattimento. Studi. Milano: Giuffrè, 1956, p. 131-134.

FOSCHINI, Gaetano. Sistema del diritto processuale penale. II. $2^{\mathrm{a}}$ ed. Milano: Giuffrè, 1968.

GALLUCCIO MEZIO, Gaetano. Il principio di immediatezza è al tramonto? Cassazione Penale, 2020/1, p. 397-415. 
GARLATI, Loredana. Miti inquisitori: la confessione tra ricerca della verità e 'garanzie' processuali. In: LUPÀRIA, Luca; MARAFIOTI, Luca (a cura di). Confessione, liturgie della verità e macchine sanzionatorie. Scritti raccolti in occasione del Seminario di studio sulle 'Lezioni di Lovanio' di Michel Foucault. Torino: Giappichelli, 2015, p. 69-93.

GAROFALO, Raffaele. Criminologia. Studio sul delitto e sulla teoria della repressione [...]. 2 $2^{\mathrm{a}}$ ed. Torino: Bocca, 1891.

GAROFALO, Raffaele. I pericoli sociali di alcune teorie giuridiche. Archivio di Psichiatria, Scienze penali ed Antropologia criminale, v. 3, 1882, p. 380-393.

GERMANO, Riccardo. L'immediatezza e le sue contraddizioni: perché i principi non sono dogmi. Rivista italiana di diritto e procedura penale, v. 63, , n. 1, 2020, p. $151-177$.

GLASER, Julius. Handbuch des Strafprozesses. Erster Band. In: BINDING, Karl (hrsg.), Systematisches Handbuch der Deutschen Recthtswissenschaft [...]. Neunte Abtheilung, vierter Theil, erster Band. Leipzig: Verlag von Duncker \& Humblot, 1883.

HÉLIE, Faustin, Traité de l'instruction criminelle ou Théorie du code d'instruction criminelle [...]. Deuxième édition entièrement revue et considérablement augmentée. Tome premier. Paris: Henri Plon, 1867.

ILLUMINATI, Giulio. Il nuovo dibattimento: l'assunzione diretta delle prove. Il Foro Italiano, v. 111, n. 5, 1988, coll. 355-366.

JOHN, Richard Ed. Das Deutsche Strafprozessrecht. Mit Rücksicht auf die Justizgesetze des Deutschen Reichs in den Grundzügen systematisch dargestellt. Leipzig: Duncker \& Humblot, 1882.

JOHNES, Arthur James. Suggestions for a Reform of the Court of Chancery, by a Union of the Jurisdictions of Equity and Law: with a Plan of a New Tribunal for Cases of Lunacy. London: Saunders and Benning, 1834.

Lavori preparatorii del Codice di Procedura Penale per il Regno d'Italia. Atti della Commissione istituita con decreto 3 ottobre 1898 dal Ministro di Grazia e Giustizia e dei Culti (Finocchiaro-Aprile) con l'incarico di studiare e proporre le modificazioni da introdurre nel vigente Codice di procedura penale. Volume primo. Roma: Tipografia della Camera dei Deputati, 1900.

Lavori preparatorii del Codice di Procedura Penale per il Regno d'Italia. Atti della Commissione istituita con decreto 3 ottobre 1898 dal Ministro di Grazia e Giustizia e dei Culti (Finocchiaro-Aprile) con l'incarico di studiare e proporre le modificazioni da introdurre nel vigente Codice di procedura penale. Volume secondo. Roma: Tipografia della Camera dei Deputati, 1900. 
LESSONA, Carlo. Teoria delle prove nel diritto giudiziario civile italiano [...]. Vol. IV. Seconda edizione interamente riveduta. Firenze: Cammelli, 1908.

LORUSSO, Sergio. Il fascino indiscreto della "mediatezza". Sistema penale, 23 novembre 2020, p. 1-12.

LOZZI, Gilberto. Lineamenti di procedura penale. 10ª ed. Torino: Giappichelli, 2020.

LUCCHINI, Luigi. Elementi di procedura penale. Firenze: Barbèra, 1895.

LUCCHINI, Luigi. Elementi di procedura penale. Seconda edizione riveduta e ampliata. Firenze: Barbèra, 1899.

LUCCHINI, Luigi. Elementi di procedura penale. Terza edizione riveduta e ampliata. Firenze: Barbèra, 1905.

LUCCHINI, Luigi. Elementi di procedura penale. Quarta edizione interamente riveduta e ampliata. Firenze: Barbèra, 1920.

LUCCHINI, Luigi. Pubblicità oralità e contraddittorio della istruttoria del processo penale. Appunti critici [...]. Estratto dal Giornale Giuridico «La Rivista». Verona: Tipografia M. Dal Ben, 1873.

LUCCHINI, Luigi. I semplicisti (antropologi, psicologi e sociologi) del diritto penale. Saggio critico. Torino: Unione Tipografico-Editrice, 1886.

LUONGO, Dario. La «nuova legislazione» e l'eredità dell'antico regime: percezioni storiografiche nella cultura giuridica meridionale dell'Ottocento. In: MASTROBERTI, Francesco; MASIELLO, Gaia (a cura di). Il Codice per lo Regno delle Due Sicilie. Elaborazione, applicazione e dimensione europea del modello codicistico borbonico. Napoli: Editoriale Scientifica, 2020, p. 321-428.

MANDUCA, Filippo. Gli anonimi ed il giudizio penale. Pensieri. Il Filangieri, v. 9 , n. 1, 1884, p. 552-562.

MANDUCA, Filippo. La procedura penale e la sua evoluzione scientifica. Napoli: Ernesto Anfossi, 1888.

MANZINI, Vincenzo. Trattato di procedura penale italiana secondo il nuovo c.p.p.e le nuove leggi di ord. giud. - Volume II. Torino: Fratelli Bocca, 1914.

MANZINI, Vincenzo. Trattato di diritto processuale penale italiano secondo il nuovo codice. Con prefazione di Alfredo Rocco Ministro della Giustizia. Volume terzo. Torino: Unione Tipografico-Editrice Torinese, 1932.

MANZINI, Vincenzo. Trattato di diritto processuale penale italiano secondo il nuovo codice. Con prefazione di Alfredo Rocco Ministro della Giustizia. Volume quarto. Torino: Unione Tipografico-Editrice Torinese, 1932. 
MASSA, Carlo. Il principio dell'immediatezza processuale. In: Studi in onore di Biagio Petrocelli. Tomo secondo. Milano: Giuffrè, 1972, p. 1119-1150.

MASSA, Michele. Contributo all'analisi del giudizio penale di primo grado. Milano: Giuffrè, 1964.

MASSARI, Eduardo. Il Processo Penale nella nuova Legislazione Italiana. Libro I [...]. Napoli: Jovene, 1934 [ma 1932].

MAZZA, Oliviero. Tradimenti di un codice. La Procedura penale a trent'anni dalla grande riforma. Torino: Giappichelli, 2020.

MILETTI, Marco Nicola. Un processo per la Terza Italia. Il codice di procedura penale del 1913. I: L’attesa. Milano: Giuffrè, 2003.

MILETTI, Marco Nicola. Un vestito per Cenerentola. L'identità del diritto processuale penale all'alba della Repubblica. In: NEGRI, Daniele; PIFFERI, Michele (a cura di). Diritti individuali e processo penale nell'Italia repubblicana. Milano: Giuffrè, 2011, p. 363-393.

MITTERMAIER, Carl Joseph Anton. Die Mündlichkeit, das Anklageprincip, die Oeffentlichkeit und das Geschwornengericht. Stuttgart und Tübingen: Cotta, 1845.

MITTERMAIER, Carl Joseph Anton. Il processo orale accusatorio e per giurati secondo le varie legislazioni [...]. Versione dal tedesco dell'avv. M.M. con aggiunte. Volume unico. Reggio: Stefano Calderini e Comp. - Modena: Nicola Zanichelli e Comp., 1851.

MITTERMAIER, Carl Joseph Anton. Das Volksgericht in Gestalt der Schwur- und Schöffengerichte, Berlin 1866, tr. it. Il giudizio popolare nella forma del giurí e del Tribunale degli scabini secondo le moderne legislazioni. Recato in italiano dall'Avvocato Carlo Dura e pubblicato per la cura di Giuseppe Vacca [...]. Napoli: Stabilimento Tipografico di Salvatore Marchese, 1868.

NICOLINI, Niccola. Della discussione pubblica ne' giudizii penali. Discorso pronunziato alla Corte Suprema di Giustizia di Napoli a camere riunite [...] nel dí 7 gennaio 1833 giorno solenne del riaprimento dell'anno giudiziario. Napoli: Dalla Stamperia Salita Infrascata, 1833.

NICOLINI, Niccola. Della procedura penale nel Regno delle Due Sicilie [...]. Parte seconda, vol. II. Napoli: Dalla Stamperia di M. Criscuolo, 1829.

NICOLINI, Niccola. Della procedura penale nel Regno delle Due Sicilie [...]. Parte terza Vol. II. Napoli: Dalla Stamperia di M. Criscuolo, 1831. 
NICOLINI, Niccola. Quistioni di dritto trattate nelle conclusioni, ne' discorsi ed in altri scritti legali [...]. Vol. I. Napoli: Dalla Tipografia Salita Infrascata, 1835.

ORLANDI, Renzo. Diritti individuali e processo penale nell'Italia repubblicana. In NEGRI, Daniele; PIFFERI, Michele (a cura di). Diritti individuali e processo penale nell'Italia repubblicana. Milano: Giuffrè, 2011, p. 51-83.

PAGANO, Francesco Mario. Considerazioni sul processo criminale, a cura di Filippo Maria Paladini. Prefazione di Vincenzo Ferrone. Venezia: Centro di Studi sull'Illuminismo europeo "G. Stiffoni”, 2009.

PETROCELLI, Biagio. Azione - istruzione - accusa. Rivista Penale, fsc. 1-2, 1931, p. 226 ss., ora in PETROCELLI, Biagio. Saggi di diritto penale. Padova: Cedam, 1952, p. 573-607.

RAFARACI, Tommaso. Processo penale tedesco. In: Enciclopedia del diritto. Annali. II/1. Milano: Giuffrè, 2008, p. 831-859.

SALA, Erio. Dell'intervento dell'imputato nella istruzione del processo penale. Rivista Penale, vol. 5, fsc. ago., 1876, p. 5-31.

SALUTO, Francesco. Commenti al codice di procedura penale per il Regno d'Italia [...]. Volume III. $2^{\mathrm{a}}$ ed. Torino: Bocca, 1877.

SIRACUSANO, Delfino; GALATI, Antonino; TRANCHINA, Giovanni; ZAPPALÀ, Vincenzo. Diritto processuale penale, II. Milano: Giuffrè, 2011.

STOPPATO, Alessandro. Relazione della Commissione nominata dal presidente della Camera composta dei deputati Grippo presidente, Dari segretario, Barzilai, Daneo, Ferri Enrico, Fulci, Girardi, Muratori e Stoppato relatore sul progetto del codice di procedura penale per il Regno d'Italia e sul disegno di legge che ne autorizza la pubblicazione approvato dal Senato del Regno il 7 marzo 1912 (v. stampato n. 544) presentato dal ministro di grazia e giustizia e dei culti nella tornata dell'8 marzo 1912. In: MORTARA, Lodovico; STOPPATO, Alessandro; VACCA, Guglielmo; SETTI, Augusto; DE NOTARISTEFANI, Raffaele; LONGHI, Silvio (a cura di). Commento al Codice di procedura penale. Parte Prima - Lavori preparatorii. Volume terzo. Lavori parlamentari (relazioni, discussioni) e redazione definitiva del Codice e delle norme di attuazione e transitorie. Torino: Unione Tipografico-Editrice Torinese, 1914, p. 185-342.

STORTI STORCHI, Claudia. Difetti del sistema e difetti d'uomini. Citazione diretta e logica dell'istruzione dal codice di procedura penale del 1865 alle soglie della pubblicazione del codice del 1913. In: MILETTI, Marco Nicola (a cura di). Riti, tecniche, interessi. Il processo penale tra Otto e Novecento. Atti del convegno (Foggia, 5-6 maggio 2005). Milano: Giuffrè, 2006, p. 227-263. 
SURACI, Leonardo. La parabola dell'immediatezza nel processo penale. Penale. Diritto e Procedura, 18/2/2020, p. 1-15.

UBERTIS, Giulio. Dibattimento (principi del) nel diritto processuale penale. In: Digesto delle discipline penalistiche, III. Torino: Utet, 1987, p. 453-466.

VILLA, Tommaso. Circolare (N. 868) del Ministero di Grazia e Giustizia e dei Culti, 25 gennaio 1880. Vantaggi derivanti dalla citazione diretta nei procedimenti penali. In: Collezione celerifera delle leggi, decreti, istruzioni e circolari dell'anno 1880 ed anteriori, LIX. Roma: Presso gli Editori, via S. Uffizio 1, 1880, p. 369-373.

VILLA, Tommaso; LOPEZ, Filippo; DE BENEDETTI, G.C.; GRIPPO, Pasquale. Corte di Cassazione penale - Per Paride Fioravanti - Motivi del ricorso - Udienza del 22 giugno 1891. Roma: Tipografia Cooperativa Operaia, 1891.

VON KRIES, August. Lehrbuch des Deutschen Strafprozessrechts. Freiburg: Akademische Verlagsbuchhandlung von J.C.B. Mohr, 1892.

VON KRIES, August. Das Prinzip der Unmittelbarkeit im Beweisverfahren der Deutschen Prozessordnung. Zeitschrift für die gesamte Strafrechtswissenschaft, v. 6, 1886, p. 88-203.

\section{Additional information and author's declarations (scientific integrity)}

Conflict of interest declaration: the author confirms that there are no conflicts of interest in conducting this research and writing this article.

Declaration of authorship: all and only researchers who comply the authorship requirements of this article are listed as authors; all coauthors are fully responsible for this work in its entirety.

Declaration of originality: the author assures that the text here published has not been previously published in any other resource and that future republication will only take place with the express indication of the reference of this original publication; he also attests that there is no third party plagiarism or self-plagiarism. 


\section{Editorial process dates}

(http://www.ibraspp.com.br/revista/index.php/RBDPP/about/editorialPolicies)

- Submission: 30/05/2021

- Desk review and plagiarism check: 05/06/2021

- Review 1: 13/06/2021

- Review 2: 15/06/2021

- Preliminary editorial decision: $17 / 06 / 2021$

- Correction round return: 02/07/2021

- Final editorial decision: 07/07/2021

\section{Editorial team}

- Editor-in-chief: 1 (VGV)

- Associated-editor: 2 (RS e GM)

- Reviewers: 2

\section{HOW TO CITE (ABNT BRAZIL):}

MILETTI Marco Nicola. Le facce d'un diamante. Appunti per una storia dell'immediatezza nella procedura penale italiana. Revista Brasileira de Direito Processual Penal, vol. 7, n. 2, p. 827-882, mai./ago. 2021.

https://doi.org/10.22197/rbdpp.v7i2.596

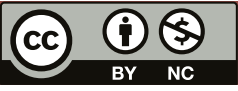

Esta obra está licenciada com uma Licença Creative Commons Atribuição-NãoComercial 4.0 Internacional. 